\title{
1 Experimental and Analytical Assessment of the Flexural Behaviour of Cantilevered RC Walls Subjected to Impact Actions
}

\author{
Arnold C.Y. Yong ${ }^{1}$, Nelson T.K. Lam², Scott J. Menegon ${ }^{3}$ and Emad F. Gad ${ }^{4}$
}

\section{Abstract}

5 Reinforced concrete (RC) impact-resistance barriers, such as rockfall barriers, often consist of

6 a cantilever RC wall, which is expected to experience flexural bending under impact loading

7 to resist the associated design actions. In order to investigate the flexural response behaviour

8 of an RC cantilever wall, a large-scale experiment was carried out on a fixed base RC

9 cantilevered barrier wall measured $1.5 \mathrm{~m}$ in height, $3 \mathrm{~m}$ in length and $0.23 \mathrm{~m}$ in thickness. Two "torpedo" shaped steel impactors with mass of $280 \mathrm{~kg}$ and $435 \mathrm{~kg}$ were released from controlled heights ranging from $0.2 \mathrm{~m}$ to $1.4 \mathrm{~m}$ in pendulum style to strike the top of the wall. The first half of this paper presents an overview, findings and results of this large-scale, original experimental work. The second half of the paper presents a displacement-based analytical model, which can be used to assess and determine important design parameters for cantilever RC barrier walls of this nature; including, deflection demand and material strains. Systematic comparisons of the experimental results and the proposed analytical model demonstrate the accuracy and reliability of the proposed model for assessing cantilevered RC barrier walls subject to impact actions.

19 Keywords: large-scale impact test; displacement-based, reinforced concrete, rockfall barrier

\footnotetext{
${ }^{1}$ Research Fellow, Department of Infrastructure Engineering, The University of Melbourne, Parkville, Victoria 3010, Australia. Email: arnold.yong@unimelb.edu.au.

${ }^{2}$ Professor, Department of Infrastructure Engineering, The University of Melbourne, Parkville, Victoria 3010, Australia.Email:ntkl@unimelb.edu.au.

${ }^{3}$ Research fellow, Department of Civil and Construction Engineering, Swinburne University of Technology, Hawthorn, Victoria 3122, Australia. Email: smenegon@ swin.edu.au.

${ }^{4}$ Professor, Dean of School of Engineering, Faculty of Science Engineering and Technology, Swinburne University of Technology, Hawthorn, Victoria 3122, Australia. E-mail: egad@swin.edu.au.
} 
21 Impact actions need to be considered in the design of reinforced concrete (RC) rockfall barriers, which are exposed to actions of landslide debris and boulder impact. As shown in field measurements, the amplitude of transient forces generated by the impact of boulders can be several orders of magnitude higher than forces that are associated with fluid pressure generated by debris flow (Hu et al. 2006, Hu et al. 2011, Zhang 1993). The cantilevered wall component of a RC barrier is commonly designed in accordance with force-based approaches (e.g. American Association of State Highway and Transportation Officials (2012), ASTRA (2008), Austroads (2013), Japan Road Association (2000), Kwan (2012), Standards Australia (2004)), which involve applying a pre-determined quasi-static force on the targeted structure. In reality, the impact force developed at the point of contact between the boulder and the surface of the concrete is usually of very high intensity but lasts only for a very short duration, unlike the quasi-static force to be used in design (Perera et al. 2016, 2017, Sun et al. 2014). If the highly transient contact force is to be simulated, the inertial resistance developed in the target (i.e. the concrete barrier) must also be simulated in order to accurately predict the resulting flexural response behaviour of the cantilevered $\mathrm{RC}$ wall. An alternative approach to the design of an impact resistant barrier is to employ the equal energy approach; wherein the amount of energy delivered by the impactor is equated to the energy of absorption of the wall, which is associated with the bending of the cantilevered wall (Eurocode 1 2008, Jiang et al. 2004). This equal energy approach may over-state the flexural action if mitigating effects such as dissipation of energy on impact and inertial resistance generated from within the wall have not been accounted for. Both force-based and equal energy approaches as described can result in an overly-conservative design of the RC barrier (Kishi et al. 2009, Lam et al. 2018a). 
43 In view of the shortcomings of existing guidelines for design and analysis, a displacementbased (DB) procedure has been developed as an alternative method of assessing impact actions. Undertaking major repair work on a failed barrier which is adjacent to a highway, or a train track, can be very disruptive and hence costly. The proposed assessment procedure is therefore based on pre-yield conditions of the RC wall with a view to limit the amount of repair work following an impact incident. The DB method is aimed at making accurate predictions of the displacement demand of the impacted wall in pre-yield conditions. The proposed model has previously been validated using small-scale experimental testing, which involved dropping a small impactor object onto a mild steel bar or a wooden joist (e.g. Ali et al. (2014), Lam and Gad (2016), Lam et al. (2018b), Yang et al. (2012)). This paper will present an experimental validation of the proposed $\mathrm{DB}$ model using a large-scale $\mathrm{RC}$ wall test specimen. The experimental validation of the proposed algebraic expression for predicting the displacement demand of the impact is an achievement of high practical significance.

Apart from considerations of flexural failure of the impacted wall, risks of failure by punching (shear) or by other phenomena localised around the point of contact also requires assessment, and much depends on the nature of the impact. Assessment of risks associated with these localised phenomena deserves separate treatment and is outside the scope of considerations of the article. Some relevant experimental investigations were carried out and reported by authors such as Dancygier et al. (2007), Heckötter and Vepsä (2015), Kojima (1991), Zhang et al. (2005). These experiments normally involved the use of gas gun or gun powder to fire the impactor. Such setup allows much higher impact velocity as compared to the drop hammer setup or pendulum setup used in this paper. However, the impactor mass is limited to the capacity and operation range of the gas gun/power gun. Studies focused on the localised impact response behaviour of concrete are low impactor mass and high impact velocity in nature, as opposed to the studies on global behaviour (e.g. this paper) which involve the use of much 
heavier impactor at a lower impact velocity. An experimental work on low velocity penetration has been reported by Tamagna and Riera (1993). Based on the test results, empirical and semiempirical formula have been developed which relate contact force (or stress) to penetration depth (Tamagna and Riera 1998), and the relationship was to found to be affected by both the impactor material and contact surface.

Experimental investigations of different scales have been carried out over the years to better understand the behaviour of RC structures to impact actions. Many of these tests made use of a simply-supported beam (Fujikake et al. 2009, Kishi and Bhatti 2010, Tachibana et al. 2010, Zhan et al. 2015) or a RC slab (Chen and May 2009, Hummeltenberg et al. 2011, Mougin et al. 2005, Othman and Marzouk 2016, Zineddin and Krauthammer 2007) as the targeted specimen. These tests were typified by the use of a drop hammer, or the like, and hence not ideal for validating an analytical model for simulating, say, the horizontal impact of a boulder on a rockfall barrier. Some studies involved large scale horizontal impact testings in the field but little instrumental data were captured (Ahmed et al. 2013, Aminata et al. 2008, ElSalakawy et al. 2002, Ng et al. 2016), since the level of instrumentation can be compromised by the scale of the experiment. Much of the tests reported in literature did not take direct measurement of the bending action of the wall in the form of material strains (e.g. neither data on displacement nor material strains were captured in tests carried out by Su et al. (2015)). Currently, the literature on the design of barriers to impact actions has no experimentally validated provisions for determining the tensile stresses and strains on the longitudinal reinforcement for resisting bending actions.

The DB model to be introduced in this article for predicting the displacement demand of the 90 impact considers inertial effects as well as energy losses occurring on impact, and has been 91 shown to provide accurate estimates of the maximum deflection of a target when subjected to 
the impact of a moving object up to the limit of yield of the target. The predictive expression has been validated by a $1.5 \mathrm{~m}$ tall and $3 \mathrm{~m}$ long fixed base $\mathrm{RC}$ barrier which was wellinstrumented to take measurements of the deflection of the wall and the tensile strains of the longitudinal reinforcements along the length of the wall. A pendulum device that was fitted with a torpedo-shaped solid steel impactor was used to deliver horizontal impact to the top of the cantilevered wall. The experimental investigation was scoped to cover pre-yield conditions of the wall. Details of the specimen, impactors, instrumentation, experimental set up and procedures will be described in this paper followed by a summary of the results from the impact tests. The second half of the paper presents the derivation and use of expressions for predicting maximum displacement of the cantilevered RC walls subjected to impact actions. The expressions can also be used to determine maximum tensile strain of the vertical reinforcement.

\section{Experimental Impact Testing of RC Wall}

\subsection{General Set Up}

105 The RC barrier specimen had a cantilevered wall with dimensions of $1.5 \mathrm{~m}$ tall, $3 \mathrm{~m}$ long and $1060.23 \mathrm{~m}$ thick. The wall was cast on top of a wall footing of $0.5 \mathrm{~m}$ thick and $1.23 \mathrm{~m}$ wide, as shown in Figure 1 (a). Standard strength grade N40 concrete to AS 1379 (Standards Australia 2007), which had a minimum characteristic compressive strength of $40 \mathrm{MPa}$ (based on 28 days of standard curing), was used to construct the specimen. The concrete mix had standard density

110 of $2400 \mathrm{~kg} / \mathrm{m}^{3}$ and maximum aggregate size of $20 \mathrm{~mm}$. Compression tests were carried out on

111 six concrete cylinders during the time the impact tests were carried out and the in-situ concrete strength was found to be $47 \mathrm{MPa}$.

113 Grade D500N reinforcing steel bars to AS/NZS 4671 (Standards Australia and Standards New

114 Zealand 2001) were used as vertical and horizontal reinforcement in the wall, as well as in the

115 wall footing, as shown in Figure 1 (b). The minimum characteristic yield strength and the strain 
116 hardening ratio of these reinforcing bars were $500 \mathrm{MPa}$ and 1.08 respectively. N20 (i.e. grade

117 D500N with nominal diameter of $20 \mathrm{~mm}$ ) bars at $200 \mathrm{~mm}$ spacing were used for both the

118 vertical and horizontal reinforcement in the wall. There were 15 tensile bars and 15

119 compressive bars in total. Similar reinforcement arrangement was used for the wall footing to

120 ensure that the cantilevered wall was fixed rigidly to the foundation which was in turn held

121 down onto the strong floor of the laboratory. Tensile tests were carried out on six bar samples

122 to obtain the in-situ material properties of the reinforcement, which was as follows: yield stress

123 of $543 \mathrm{MPa}$; $636 \mathrm{MPa}$; strain hardening ratio of 1.17 ; ultimate strain of $9.6 \%$; and elastic

124 modulus of $194,000 \mathrm{MPa}$. Concrete cover of $30 \mathrm{~mm}$ was specified. The wall had a

125 reinforcement ratio of more than $0.8 \%$ for grade $\mathrm{N} 40$ concrete, which ensured that the concrete

126 would experience a well distributed crack pattern when subject to flexural actions (Menegon

127 et al. 2018).

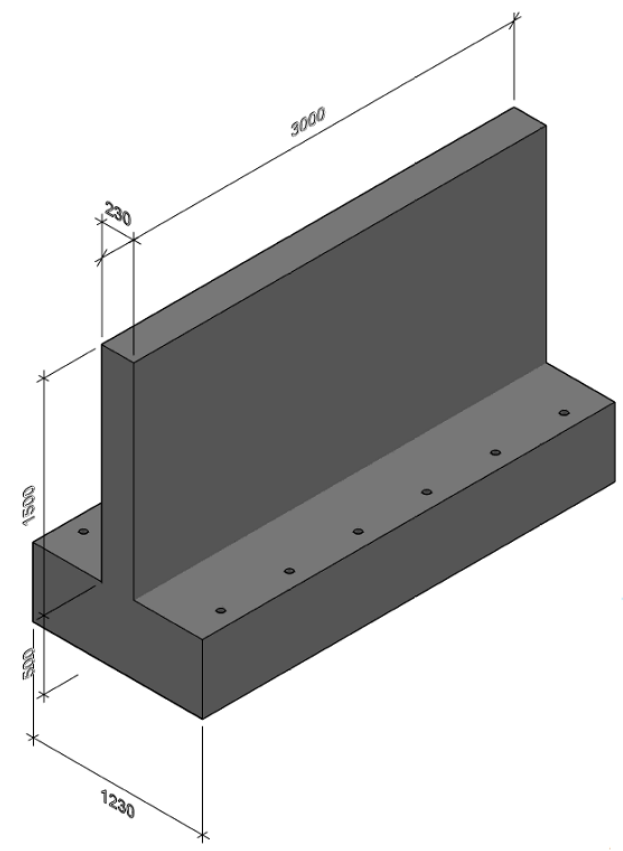

(a)

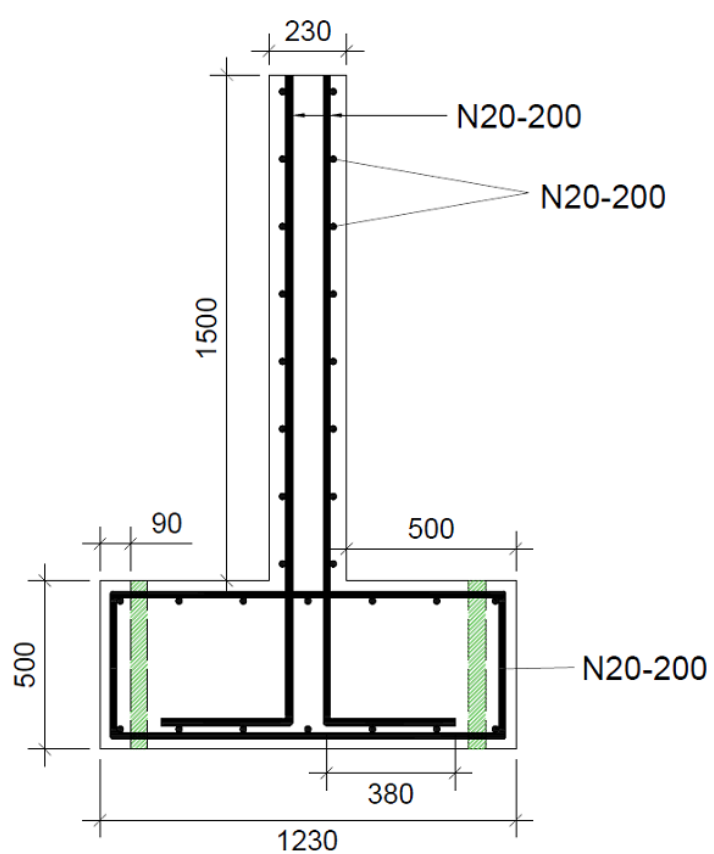

(b) 
130 Two impactors made of solid steel with density of $7850 \mathrm{~kg} / \mathrm{m}^{3}$ were used to strike the RC

131 barrier wall specimen. Solid steel "torpedo" shaped objects (with a hemispherical surface at

132 the point of contact) were employed as impactor objects in order that the impact tests are both

133 repeatable and reproducible. The hemispherical fitting had the same diameter as the cylindrical

134 body. At the other end (flat end), a 1/4-28 UNF-2B hole was tapped for securing an

135 accelerometer to the impactor object. On the curved cylindrical surface, three M20 holes were

136 tapped for the purpose of lifting, with the middle hole tapped at the centre of mass of the

137 impactor. Eye nuts were secured onto the holes. The flexural response behaviour of the stem

138 wall was mainly dependent on the amount of kinetic energy delivered by the strike and the

139 mass ratio $\lambda$ (i.e. target mass / impactor mass). The mechanical properties of the impactor

140 material such as compressive stiffness behaviour and projectile shape had no significant

141 influence except for the re-bounce behaviour affecting energy losses. It is widely recognised

142 that the shape of the impactor can be a controlling factor in the prediction of localised damage

143 (Adeli and Amin 1985, Ben-Dor et al. 2006, Perera et al. 2016). This factor becomes less

144 dominant in predicting the response of the wall to the impulsive action of the impact (affecting

145 the wall bending and stability behaviour) which is the subject matter of interest in this article.

146 Shape effects may still have some minor influence on the re-bounce behaviour of the impact in

147 the context of predicting bending actions of the wall. Such influences can be incorporated into

148 the proposed predictive model through the coefficient of restitution parameter (refer Section

149 3). Thus, the deflection behaviour of the test wall generated by the impact of a piece of boulder

150 can be emulated by the use of a solid steel impactor of the same weight and delivering the same

151 amount of impact energy. The impactors are numbered and summarised in Table 1 and

152 alongside in Figure 2, which shows the dimensions of the impactor object. A photograph of the

153 impactor objects is shown in Figure 3. 
156

\begin{tabular}{cccc}
\hline Impactor & Mass $(\mathrm{kg})$ & $\mathrm{a}(\mathrm{mm})$ & $\mathrm{b}(\mathrm{mm})$ \\
\hline Impactor 1 & 280 & 400 & 300 \\
Impactor 2 & 435 & 700 & 300 \\
\hline
\end{tabular}

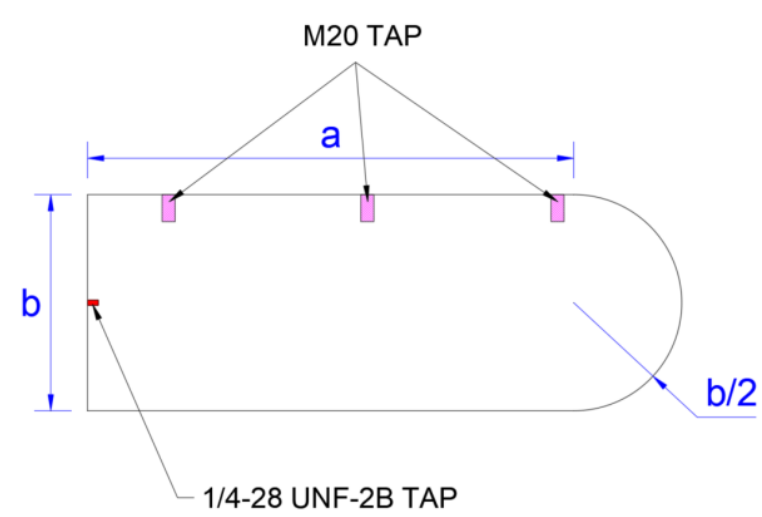

Figure 2 Torpedo shaped impactor object

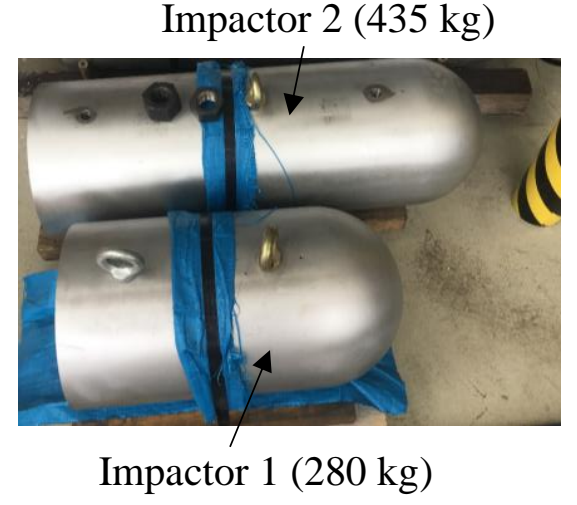

Figure 3 Photograph of impactor objects

157 Instrumentation (as shown in Figures 4 (a) and (b)) was used to capture displacement data, 158 material strains and curvatures of the dynamically responding barrier as well as the velocity of 159 the impactors over the course of impact. This included:

160 - Post-yield strain gauges which were attached to the base of the wall on each 161 longitudinal reinforcing bar. These strain gauges were designed to measure the strain in the longitudinal bars when subject to both elastic and inelastic (post-yield) strains. A trial run of the test showed that the resolution of the strain gauges was in approximately of \pm 1 micro-strain.

- Linear variable differential transformers (LVDTs) were attached to the concrete surface on both sides of the wall to measure longitudinal concrete strain up the height and along the base of the stem wall.

- Laser sensors with measurement frequency of up to $750 \mathrm{~Hz}$ were placed behind the specimen to measure deflection at various location across the width and up the height 

Additional sensors were used to detect any unintended sliding and uplift movement of the specimen, which were expected to be negligible as the specimen was supposedly fully fixed to the ground. A total of 12 pieces of laser displacement sensors were adopted in the testing.

- An accelerometer with measurement range of up to $2500 \mathrm{~g}$ and frequency response of up to $10 \mathrm{kHz}$ was screwed onto the flat end of the impactor objects (1/4-28 UNF-2B tapped hole) to record the acceleration time-history as shown in Figure 4 (b). The recorded results were then multiplied by the mass of impactor to calculate the amount of contact force that was delivered at the point of contact in an impact.

- A high speed camera (HSC), which was capable of recording video images at a rate of up to 25,000 frames-per-second at full resolution of $1280 \times 800$, was used to capture images taken at the impact location in order to: (i) determine the velocity of the impactor prior to and following impact with the wall; and (ii) visualise actual conditions (at the point of contact) during the course of the impact. The frame that was recorded by the HSC is shown in Figure 4 (b) as a green box.

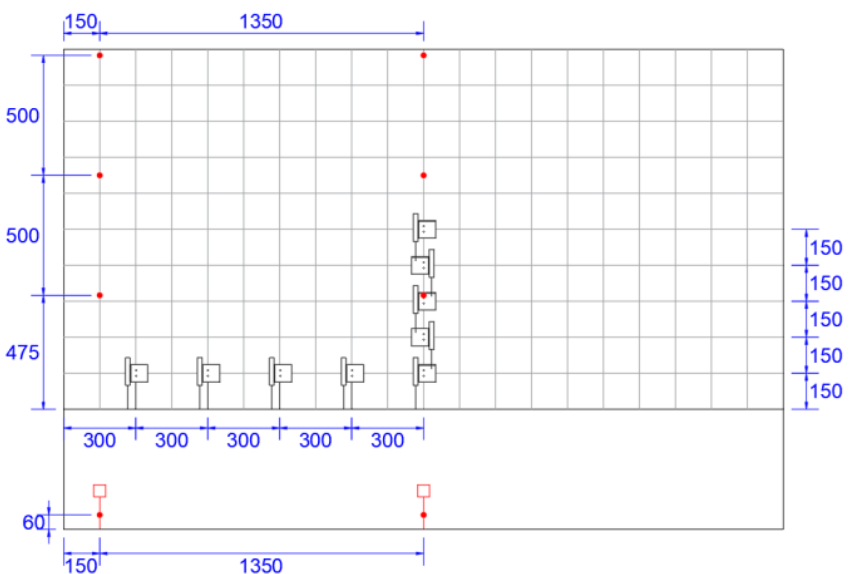

(a)

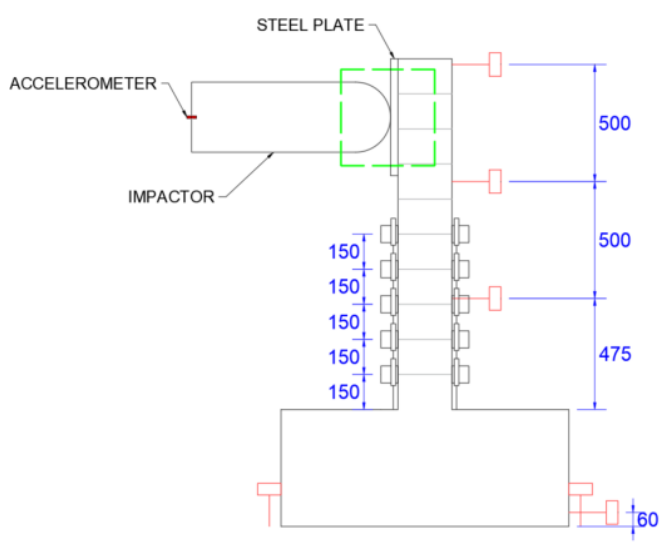

(b) instrumentation (units of length in $\mathbf{m m}$ ) 
188 A 3D drawing displaying an overview of the planned test set-up including the specimen, the 189 impactor objects and details of the instrumentation is shown in Figure 5, alongside a 190 photograph showing the actual test set-up featuring two steel frames fixed to the ground (Figure

191 6). The first steel frame that was positioned close to the specimen was used to secure the 192 impactor object in place. Each impactor object was initially positioned at the centreline of the 193 specimen and at $250 \mathrm{~mm}$ from the top of the wall. A quick release hook was attached to its 194 centre of mass. The hook was in turn secured to a cable extending from a hand winch via a 195 pulley which was attached to the second steel frame. During the course of lifting, a laser level

196 was used to ensure that the impactor had been raised to the desired height with good accuracies.

197 The impactor was then released using the quick release hook. In order to ensure a fully fixed 198 foundation, the wall footing of the barrier specimen was bolted to the strong floor of the 199 laboratory (which is approximately $1 \mathrm{~m}$ thick) using six threaded M36 rods on both sides of 200 the wall. Each of these threaded rods was post-tensioned to $200 \mathrm{kN}$ to prevent any uplift or 201 sliding of the foundation.

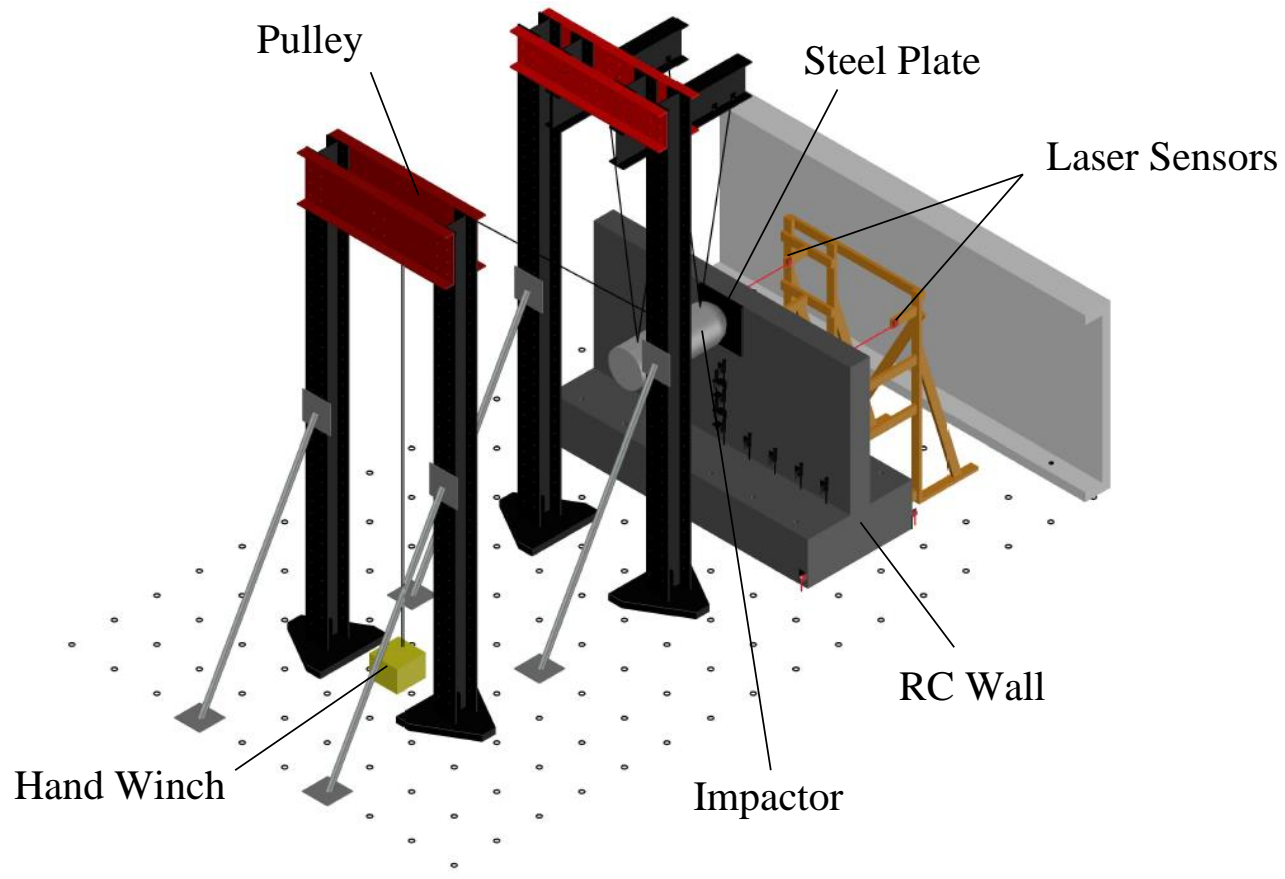




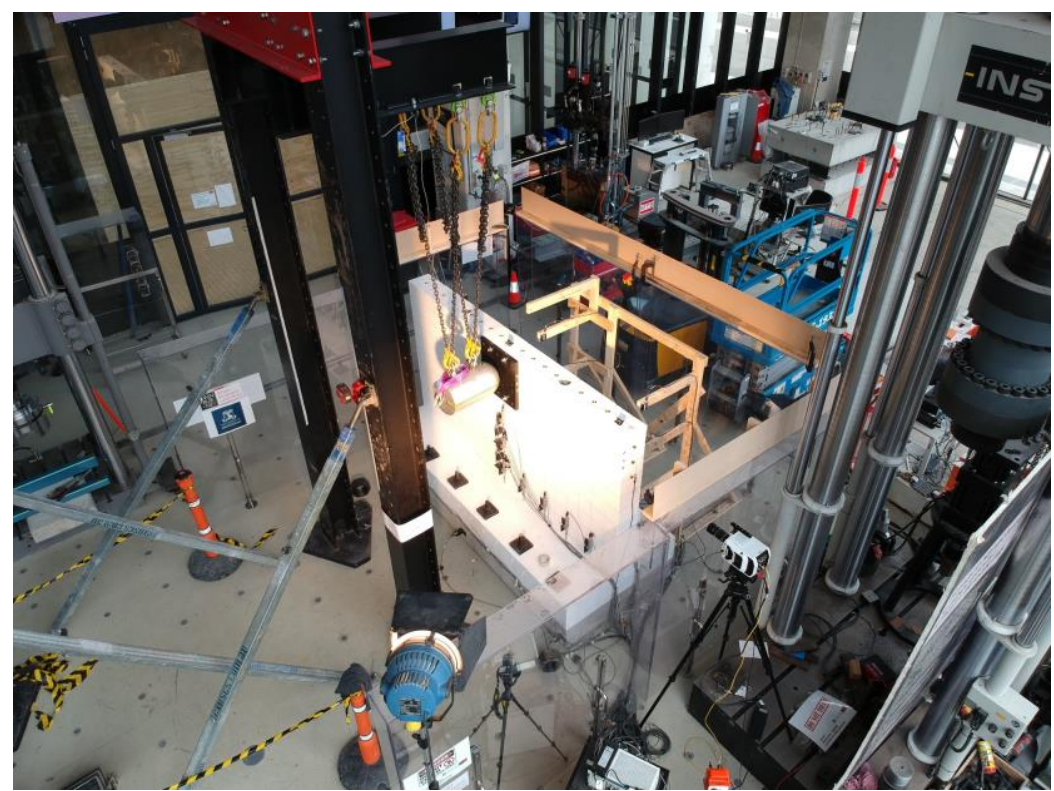

Figure 6 Photograph showing overview of test set up

\subsection{Testing Protocol}

207 The wall specimen was tested repeatedly to fulfil the objective of studying the change in the

208 deflection demand on the wall and the associated tensile strain demand on the longitudinal 209 reinforcement with changes in (i) amount of kinetic energy delivered by the impact, (ii) mass

210 of the impactor or target (and hence ratio of target mass : impactor mass), (iii) material at the

211 contact surface, and (iv) state of crack of concrete.

212 The first part of the test was carried out with a protective steel plate with dimensions: $500 \times 500$

$213 \mathrm{~mm} \times 32 \mathrm{~mm}$ thick, which was attached to the top of the wall at the location of impact, as

214 shown in Figures 4 (b) and 6. This steel plate was used to ensure that the bending behaviour of

215 the wall was comparable across multiple tests without being distorted by cumulative localised

216 damage surrounding the point of contact. Strain and deflection profiles of the wall were

217 constantly monitored to confirm that the wall had not yielded. Eight tests (i.e. 8 impacts to the

218 wall) were carried out in the first part of the test and these tests were numbered as Test \#1 to

219 \#8. Impactor 1 was used to strike the steel plate from various increasing release heights $\mathrm{H}$

220 (Figure 7) in Test \#1 to \#4 to deliver different amount of impact energy. Test \#5 to \#7 used 
221 Impactor 2. The drop heights for Impactor 2 were selected such that the theoretical impact energy in Tests \#5 to \#7 were the same as Tests \#1 to \#3, respectively to investigate the effect

223 of varying the impactor mass while keeping the impact energy constant. Impact test

224 corresponding to impact energy of $3.85 \mathrm{~kJ}$ (i.e. Test \#4) was omitted for Impactor 2 because

225 the wall would be too close to the threshold of yield. Following completion of the test series

226 using Impactor 2, the final test in the first part of the test (Test \#8) was conducted using

227 Impactor 1 at $0.2 \mathrm{~m}$ release height. Test \#8 was similar to Test \#1 except that the RC wall was

228 fully cracked in Test \#8 as compared to the fresh uncracked wall in Test \#1. The purpose of

229 conducting Test \#8 was to observe how the change in flexural stiffness of the wall affected the

230 structural response.

231 In the second part of the test, the steel plate was removed in order to investigate the wall

232 response behaviour when subject to the direct impact of the torpedo shaped striker without any

233 protection. Four tests (numbered as Test \#9 to \#12) were carried out using Impactor 1 with the

234 four release heights used previously in Test \#1 to \#4. By keeping the impactor mass and release

235 height the same, the difference in wall response behaviour with and without the steel plate can

236 be observed. Details of the conditions of impact for all relevant tests are summarised in Table

$237 \quad 2$.

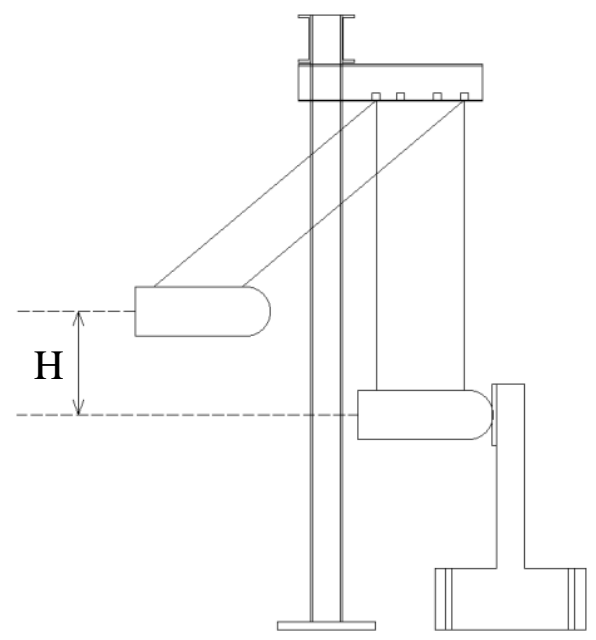




\begin{tabular}{ccccc}
\hline Test \# & $\begin{array}{c}\text { Impactor } \\
\text { Mass (kg) }\end{array}$ & $\mathrm{H}(\mathrm{m})$ & $\begin{array}{c}\text { Expected Impact } \\
\text { Energy (kJ) }\end{array}$ & Protective Layer \\
\hline 1 & 280 & 0.2 & 0.55 & Steel Plate \\
2 & 280 & 0.5 & 1.37 & Steel Plate \\
3 & 280 & 0.9 & 2.47 & Steel Plate \\
4 & 280 & 1.4 & 3.85 & Steel Plate \\
5 & 435 & 0.129 & 0.55 & Steel Plate \\
6 & 435 & 0.322 & 1.37 & Steel Plate \\
7 & 435 & 0.579 & 2.47 & Steel Plate \\
8 & 280 & 0.2 & 0.55 & Steel Plate \\
9 & 280 & 0.2 & 0.55 & N/A \\
10 & 280 & 0.5 & 1.37 & N/A \\
11 & 280 & 0.9 & 2.47 & N/A \\
12 & 280 & 1.4 & 3.85 & N/A \\
\hline
\end{tabular}

241

\subsection{Observations from the Impact Tests}

243 The maximum deflection of the wall was found by reading off from the recorded time-history

244 data and then correlated with its level up the height of the wall as shown in Figures 8 (a) and

245 (b) (for tests using Impactor 1 and 2 respectively) when a steel plate was attached to the wall

246 to receive the impact, and in Figure 8 (c) for tests on a bare wall without the protective steel

247 plate. In addition, the maximum deflection value has also been correlated with the amount of

248 impact energy as shown in Figure 9. Maximum deflection values recorded from Test \#1-8 and

249 Test \#9-12 (which are characterised by similar amount of impact energy) are compared in

250 Figure 9 to show the significant increase in the deflection of the wall when the steel plate has

251 been removed (in Test \#9-12). It is also shown that a higher ratio of the target mass : impactor

252 mass would always result in the wall deflecting less when amount of impact energy is kept the same. For example, the added mass of a steel plate would result in a higher target mass, and 
hence a higher mass ratio. The test wall would accordingly deflect less in response to the same impact. Delivering the same amount of energy using a smaller impactor (hence a higher mass ratio) would also result in a reduced deflection demand. This is evident by comparison of test results across Test \#1 and \#5; \#2 and \#6; and \#3 and \#7. In addition, Test \#1 and \#8 involved 258 the same impactor and release height but resulted in different deflection profiles. These observed differences can also be explained by the wall possessing different flexural stiffnesses when subject to different states of cracking following repetitive testing; the wall was only partially cracked in Test \#1 and more extensively cracked in Test \#8 following multiple strikes. This proposition is supported by the amount of cracking that was observed on the wall surface as shown in Figure 10 (as represented by red lines). Similar inferences can be drawn from the reinforcement strain profiles which will be presented in a later section of the paper.

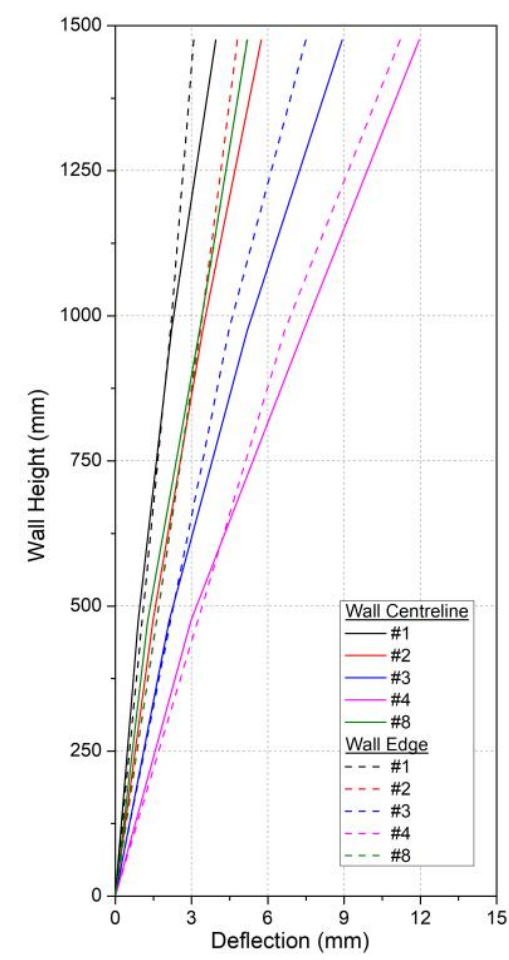

(a)

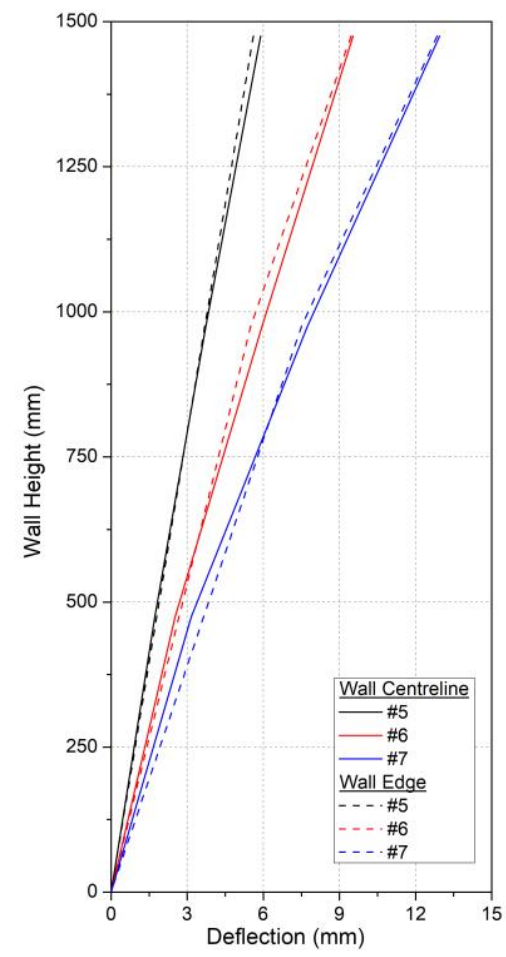

(b)

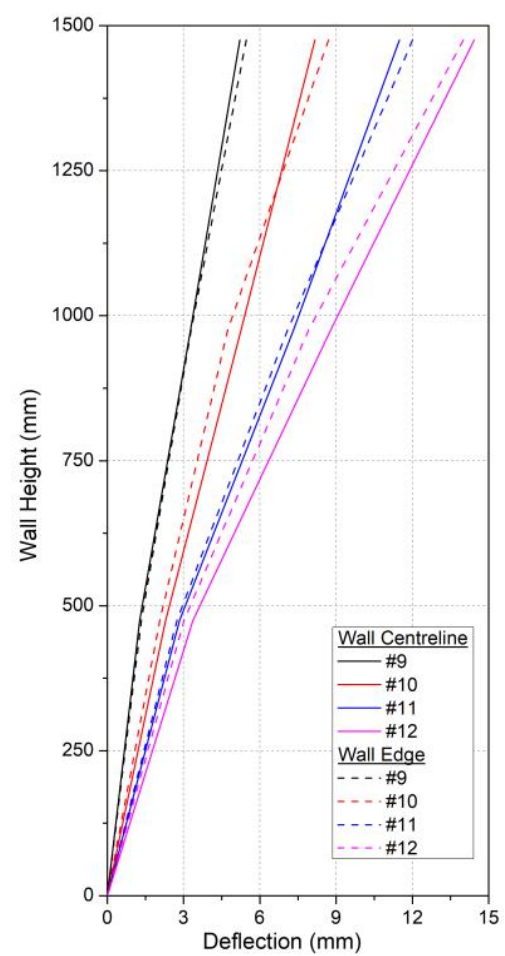

(c) steel plate employing Impactor 2, and (c) without steel plate employing Impactor 1 


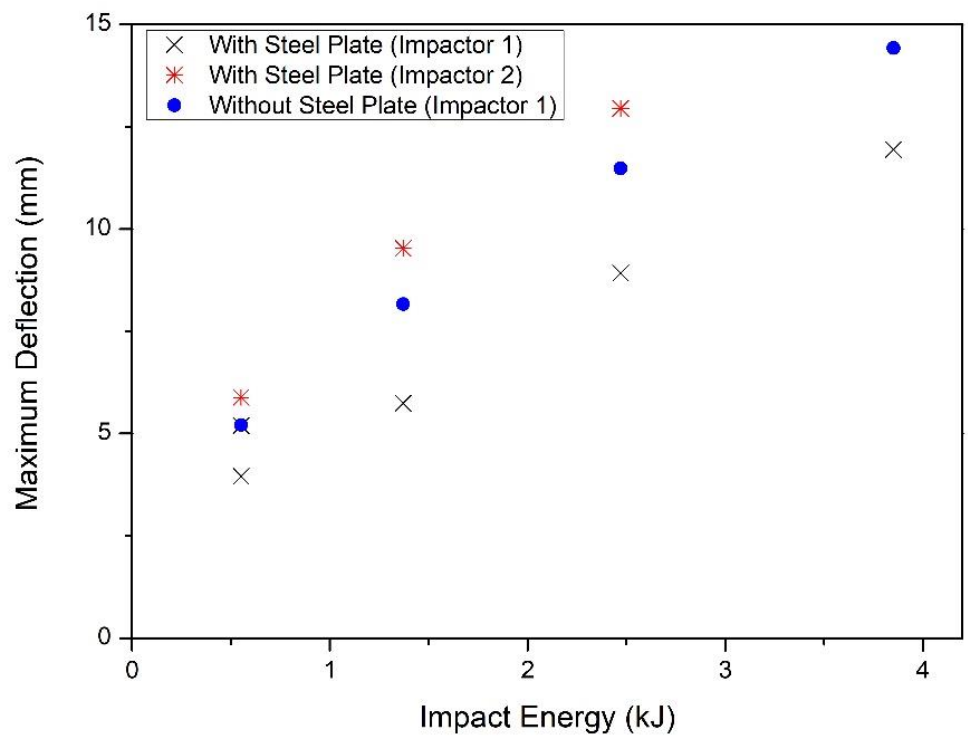

Figure 9 Maximum wall deflection vs impact energy

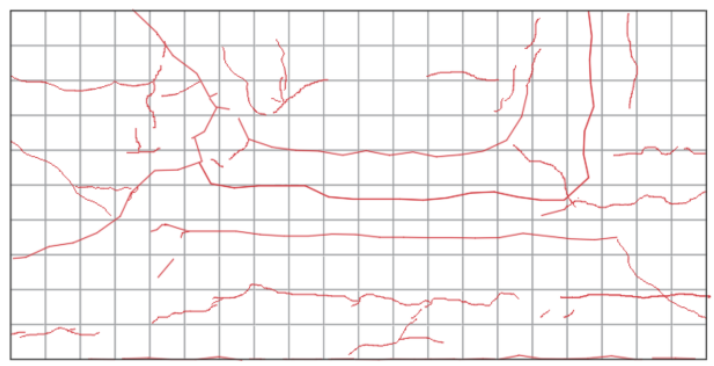

Front View (Tensile Side)

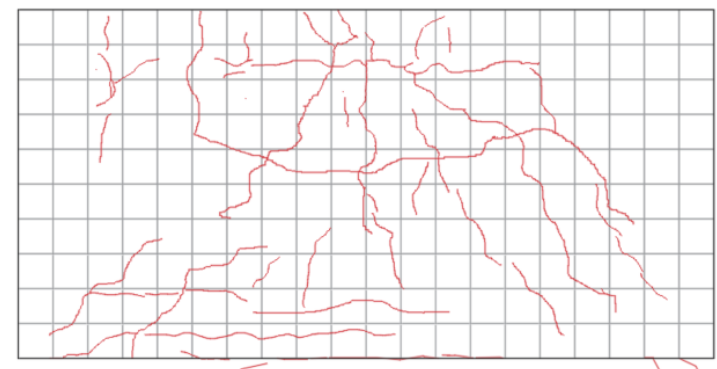

Rear View (Compressive Side)

270 The response behaviour of the wall was observed to be dominated by flexural deformation,

271 whilst minimum shear deformation was observed. The component of flexural deformation in

272 the wall was approximated by calculating a flexural deformation displacement profile of the

273 wall, which is shown in Figure 11 for Test \#7, where it can be seen to approximately equal the

274 total displacement of the wall. The flexural displacement profile was approximated by double

275 integrating the curvature profile of the wall, which was determined using LVDTs that were

276 stacked up the height of the wall at its centreline (as shown in Figures 4 (a) and (b)). Further,

277 no measurable displacement due to rocking nor sliding of the foundation was observed 278 throughout the test program, which was monitored using instrumentation mounted at the base 

wall was pre-dominantly due to flexure.

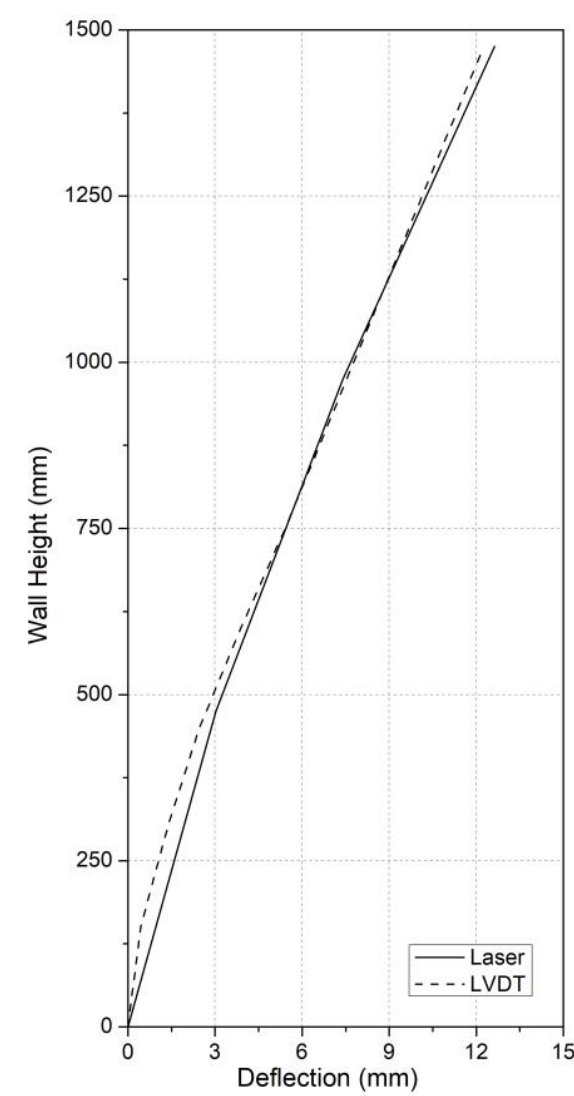

(a)

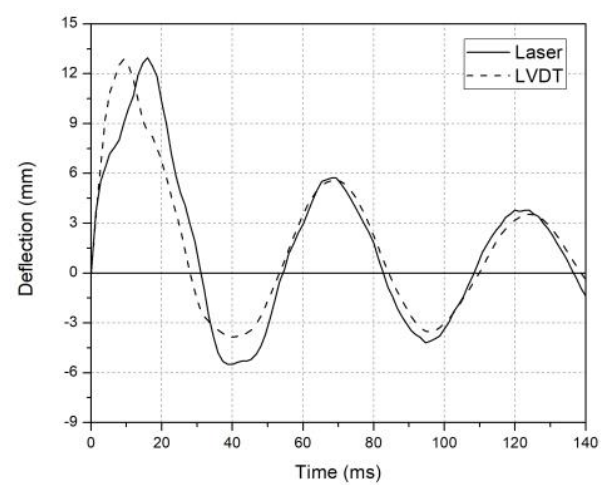

(b)

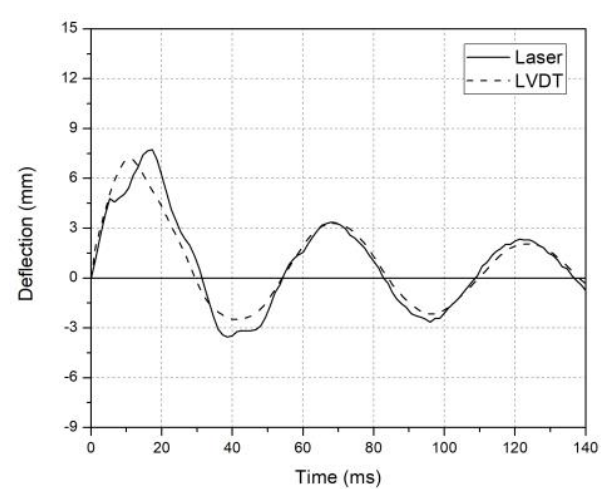

(c)

281 Figure 11 Comparison of wall deflection in Test \#7 recorded from laser and integrated from 282 LVDT results (a) along the wall height, (b) at $1475 \mathrm{~mm}$ from base, and (c) at $975 \mathrm{~mm}$ from base

283 The duration of the wall to reach its maximum strain was recorded to be between 10 to $20 \mathrm{~ms}$.

284 That corresponds to maximum strain rates of 0.05 to $0.3 \mathrm{~s}^{-1}$ for steel reinforcement and 0.04 to $0.17 \mathrm{~s}^{-1}$ for concrete, and this range of strain rate has been shown to have no significant effects on the Young's modulus of concrete (Rostasy et al. 1984, Schmidt-Hurtienne 2000) and

287 reinforcement steel (Berner 1981, Levings and Sritharan 2012). It has also been shown from the test results reported by Berner (1981), Levings and Sritharan (2012) that a strain rate of less than $0.3 \mathrm{~s}^{-1}$ would not have much significant effects on the tensile strength of the reinforcing bars. A dynamic increase factor (DIF) can be used to estimate the increase in concrete 291 compressive strength under the range of strain rate recorded from the impact tests. The value 
292 of DIF may be estimated with the use of Equation (1) for strain rate $\dot{\varepsilon}_{c}$ of less than $30 \mathrm{~s}^{-1}$ as

293 recommended by Comite Euro-Internationale du Beton (1993). Equation (1) alongside another

294 expression for $\dot{\varepsilon}_{c}$ of larger than $30 \mathrm{~s}^{-1}$ have been compared and verified based on some 30 sets

295 of test results which were collected and compiled by Bischoff and Perry (1991) from the

296 literature. In the current study, the increase in compressive strength of concrete due to strain

297 rate effect was estimated to be between 17 to $20 \%$. The effects of such a minor change in the

298 compressive strength of concrete on the impact generated deflection behaviour of the wall can

299 be neglected.

$$
\begin{gathered}
\frac{f_{c d}^{\prime}}{f_{c}^{\prime}}=\left(\frac{\dot{\varepsilon}_{c}}{30 \times 10^{-6}}\right)^{1.026 \alpha} \\
\alpha=\frac{1}{5+\frac{9 f_{c}^{\prime}}{10}}
\end{gathered}
$$

300 For Test \#9-12, the steel plate was removed from the specimen and photographs were taken at

301 the point of contact after each test to document the localised damage (Figure 12). This localised

302 damage was minor and was generally limited to only minimal surface cracks at the vicinity of

303 impact with indentation depths of less than $4 \mathrm{~mm}$. No spalling of concrete, perforation or

304 penetration were observed.

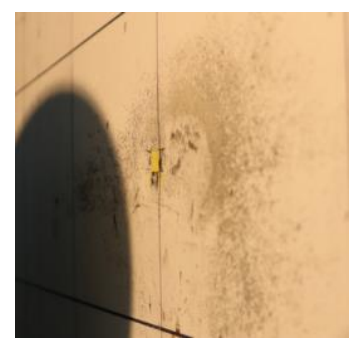

(a) Test \#9

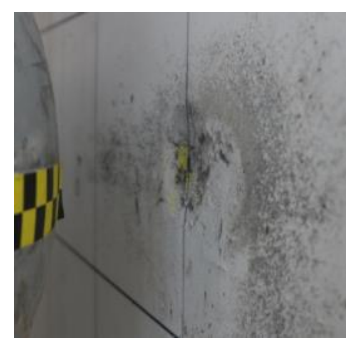

(b) Test \#10

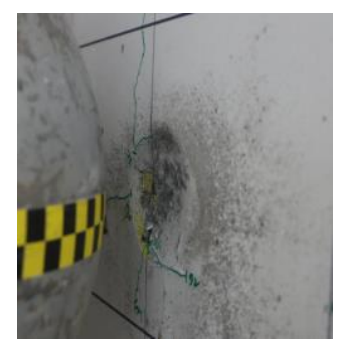

(c) Test \#11

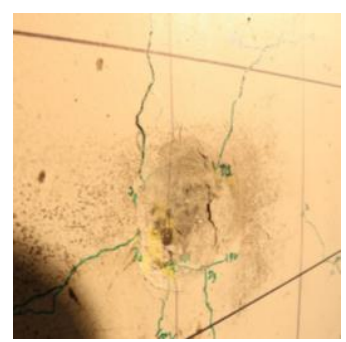

(d) Test \#12 
306 The velocity of impact can be inferred from images taken from the HSC. The measured velocity

307 values of impact $\left(v_{0}\right)$ are listed in Table 3 alongside calculated values (based on principles of

308 conservation of energy for a given height of release, i.e. $0.5 m v_{0}^{2}=m g H$ ). Discrepancies

309 between the two sets of results are shown to be minor (within 5\%). The velocity of the impactor

310 object on re-bounce $\left(v_{1}\right)$ have also been obtained from a similar manner to provide an estimate

311 of energy loss occurring over the course of the impact. It was observed that the impactor either

312 did not rebound at all but instead brought to a stop or pounding on the wall, and bouncing off

313 from it, multiple number of times. It is noted that such repetitive re-bounce behaviour was

314 immaterial to the deflection demand behaviour of the wall as the wall always deflected to the

315 maximum extent at the first strike when measurement was taken.

Table 3 Velocities prior to and following impact

\begin{tabular}{ccccc}
\hline Test \# & $\mathrm{H}(\mathrm{m})$ & Calculated $v_{0}(\mathrm{~m} / \mathrm{s})$ & Measured $v_{0}(\mathrm{~m} / \mathrm{s})$ & $v_{1}(\mathrm{~m} / \mathrm{s})$ \\
\hline 1 & 0.2 & 1.98 & 1.93 & 0 \\
2 & 0.5 & 3.13 & 3.08 & -0.26 \\
3 & 0.9 & 4.20 & 4.17 & -0.57 \\
4 & 1.4 & 5.24 & 5.18 & -0.92 \\
5 & 0.129 & 1.59 & 1.55 & -0.17 \\
6 & 0.322 & 2.51 & 2.48 & -0.34 \\
7 & 0.579 & 3.37 & 3.66 & -0.69 \\
8 & 0.2 & 1.98 & 1.91 & -0.1 \\
9 & 0.2 & 1.98 & 1.93 & -0.17 \\
10 & 0.5 & 3.13 & 3.08 & -0.34 \\
11 & 0.9 & 4.2 & 4.26 & -0.34 \\
12 & 1.4 & 5.24 & 5.1 & -0.6 \\
\hline
\end{tabular}

317 Some key experimental results are summarised and listed in Table 4. Note that the maximum

318 compressive strain in concrete and maximum curvature at the base of wall were inferred from

319 measurements of the strain gauges. 


\begin{tabular}{|c|c|c|c|c|c|c|c|c|}
\hline Test \# & $\mathrm{H}(\mathrm{m})$ & $\begin{array}{l}\text { Impactor } \\
\text { Mass (kg) }\end{array}$ & $\begin{array}{l}\text { Actual Impact } \\
\text { Energy }(\mathrm{kJ})\end{array}$ & $\begin{array}{l}\text { Maximum Wall } \\
\text { Deflection (mm) }\end{array}$ & $\begin{array}{c}\text { Contact } \\
\text { Force }(\mathrm{kN})\end{array}$ & $\begin{array}{l}\text { Maximum } \\
\text { Tensile Strain in } \\
\text { Reinforcement }\end{array}$ & $\begin{array}{c}\text { Maximum } \\
\text { Compressive Strain in } \\
\text { Concrete }\end{array}$ & $\begin{array}{l}\text { Maximum } \\
\text { Curvature at } \\
\text { Base (rad/m) }\end{array}$ \\
\hline 1 & 0.2 & 280 & 0.52 & 4.0 & 623 & 0.0007 & 0.0009 & 0.010 \\
\hline 2 & 0.5 & 280 & 1.33 & 5.7 & 931 & 0.0010 & 0.0012 & 0.013 \\
\hline 3 & 0.9 & 280 & 2.43 & 8.9 & 1208 & 0.0015 & 0.0015 & 0.018 \\
\hline 4 & 1.4 & 280 & 3.76 & 12.0 & 1485 & 0.0020 & 0.0018 & 0.022 \\
\hline 5 & 0.129 & 435 & 0.52 & 5.9 & 418 & 0.0010 & 0.0011 & 0.012 \\
\hline 6 & 0.322 & 435 & 1.34 & 9.5 & 800 & 0.0017 & 0.0015 & 0.018 \\
\hline 7 & 0.579 & 435 & 2.91 & 13.0 & 1121 & 0.0021 & 0.0017 & 0.023 \\
\hline 8 & 0.2 & 280 & 0.51 & 5.2 & 511 & 0.0009 & 0.0010 & 0.011 \\
\hline 9 & 0.2 & 280 & 0.52 & 5.2 & 315 & 0.0009 & 0.0010 & 0.011 \\
\hline 10 & 0.5 & 280 & 1.33 & 8.2 & 533 & 0.0014 & 0.0013 & 0.016 \\
\hline 11 & 0.9 & 280 & 2.54 & 11.5 & 695 & 0.0019 & 0.0016 & 0.020 \\
\hline 12 & 1.4 & 280 & 3.64 & 14.4 & 799 & 0.0023 & 0.0017 & 0.023 \\
\hline
\end{tabular}




\section{Predictions of Deflection and Bending Behaviour of Wall}

323

324

325

326

\subsection{Displacement-based Analytical Model}

A displacement-based (DB) model developed by the authors was used to predict the performance behaviour of the reinforced concrete barrier when subjected to the impact of a boulder on the cantilevered wall causing it to deflect and bend. The model was derived by the authors based on fundamental principles of energy and momentum. Analytical expressions for predicting the displacement demand of the impact have until now only been verified by impact on miniature models made of steel or wooden materials (refer Ali et al. (2014), Lam and Gad (2016), Lam et al. (2018b), Yang et al. (2012)). For the design of a RC barrier walls, which are expected to respond within the elastic limit, the model takes the form of Equation (2).

$$
\Delta=\frac{m v_{0}^{2}}{\sqrt{m k_{e f f}}} \sqrt{\lambda\left(\frac{1+\mathrm{COR}}{1+\lambda}\right)^{2}}
$$

For an impact scenario defined by the boulder mass $(m)$ and impact velocity $\left(v_{0}\right)$, the remaining input parameters to Equation (2) to be determined are the mass ratio $(\lambda)$, coefficient of restitution $(\mathrm{COR})$ and cracked stiffness $\left(k_{e f f}\right)$ of the stem wall. In the scenario where the barrier is struck by a boulder at an oblique angle $\theta, v_{0}$ is taken as the horizontal component of the actual boulder velocity $(v)$, i.e. $v_{0}=v \times \cos \theta$. Parameter $\lambda$ defines the ratio of the generalised mass of the target $(\lambda m)$ to the mass of the impactor $(m)$. The value of $\lambda m$ may be taken as a quarter of the mass of the stem wall based on established structural dynamics principles (Ali et al. 2014, Sun et al. 2016). This was derived based on the shape profile of a cantilevered wall, and will remain unaffected by crack formation as long as the limit of yield has not been surpassed. The expression of Equation (3) for determining the value of the COR parameter is based on Newton's impact hypothesis. 


$$
\operatorname{COR}=\frac{v_{1}+v_{2}}{v_{0}}
$$

343 where $v_{1}$ is the velocity of the boulder on re-bounce from the wall surface, and $v_{2}$ is the

344 velocity of the idealised lumped mass representing the responding stem wall. The value of $v_{2}$

345 can be calculated using Equation (4) which is based conservation of momentum principles.

$$
v_{2}=\frac{v_{0}+v_{1}}{\lambda}
$$

346 It is important to note that the model is applicable to fully cracked $\mathrm{RC}$ walls that remain elastic

347 (i.e. model is applicable for $M_{c r}<M<M_{y}$ ). If the impactor is not expected to crack the wall

$348\left(M<M_{c r}\right), k_{e f f}$ can simply be based on the gross stiffness $k_{g}$ to provide a more accurate

349 deflection estimate. Calculation for the value of the $k_{\text {eff }}$ parameter representing the stiffness

350 properties of the stem wall will be covered in detail in Section 3.2.

351 It is assumed in the model that the steel bars across the length of the wall are subject to uniform

352 tensile stress and strain. The effective length of the wall is taken to be twice the height of the

353 stem wall (measured above the base of the footing) based on a distribution angle of 45 degree.

354 The real behaviour of the wall is more complicated than that portrayed by the model in the sense that the tensile stresses and strains vary approximately linearly across the length of the wall reaching a maximum value at the location where the impactor strikes. The proposed model is found on the premise of providing a reasonably accurate estimate of the maximum level of stress that is experienced by the wall responding at its centreline when responding to the impact action. Refer schematic diagram of Figure 13 which illustrates the modelling concept.

360 A series of numerical simulations have been carried out by the author using program LS-DYNA

361 (details reported by Yong (2019)). It has been found that the strain distribution pattern corresponds 
to an angle of distribution of 45 degree approximately. Importantly, the numerically simulated

363 maximum tensile strain is close to estimates by the proposed analytical model which is based on

364 uniform strain assumption. In a subsequent parametric study, the numerical simulations were

365 repeated for the same stem wall but with the ratio of the reinforcement content in the horizontal to

366 vertical direction $(\mathrm{H}: \mathrm{V})$ varying between $1: 1$ to $1: 4$. The difference in the strain distribution was

367 shown to be minor. The $\mathrm{H}: \mathrm{V}$ ratio of the reinforcement content has therefore not been incorporated

368 as a design parameter in the analytical model. Consequently, the calculation procedure described herein may be adopted irrespective of the $\mathrm{H}: \mathrm{V}$ ratio of the reinforcement.

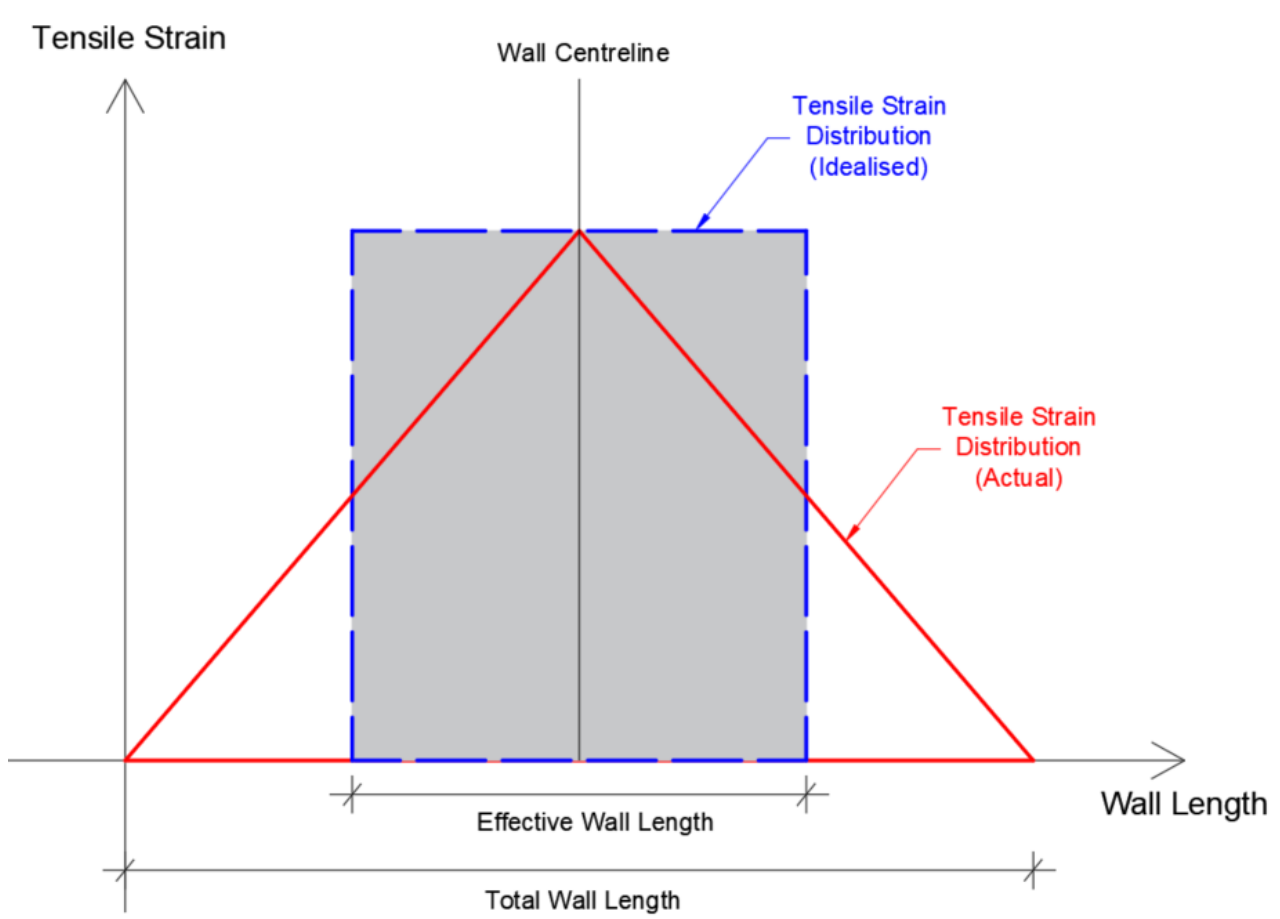

\subsection{Cracked Bending Stiffness of Reinforced Concrete Stem Wall}

373 The expression of Equation (5) for calculating the bending stiffness of a cracked reinforced

374 concrete stem wall based on structural dynamics principles is identical to the expression for

375 calculating the static stiffness of a cantilever member. 


$$
k_{e f f}=\frac{3 E I_{e f f}}{h^{3}}
$$

376 An important assumption with the calculated value of $k_{\text {eff }}$ (and hence $E I_{\text {eff }}$ ) is that it

377 represents the stiffness of the entire reinforced concrete wall. In fact, this only holds true if the

378 cracks formed on the concrete are well distributed, as shown in the schematic diagram of Figure

37914 (a) and further discussed in Menegon et al. (2018). It has been shown in the literature that

380 lightly reinforced concrete section can result in undesirable displacement behaviour as

381 distributed cracks cannot be developed (Hoult et al. 2017, Lu 2017), as shown in Figure 14 (b).

382 Menegon et al. (2018) proposed the minimum reinforcement values summarised in Table 5 to

383 ensure a desirable formation of distributed cracks. The recently revised 2018 version of the

384 Australian concrete standard, AS 3600 (Standards Australia 2018) has included similar

385 minimum reinforcement values to ensure distributed cracking in scenarios where a ductile

386 response is required. The Grade N40 RC specimen presented in Section 2 had reinforcement

387 content of approximately $1.3 \%$ and hence the minimum reinforcement requirement has been 388 met.

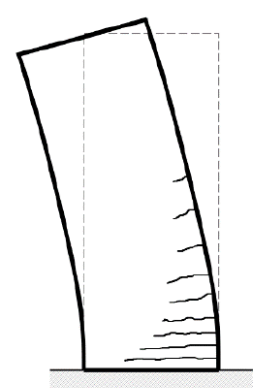

(a) traditional plastic hinge model with distributed cracking

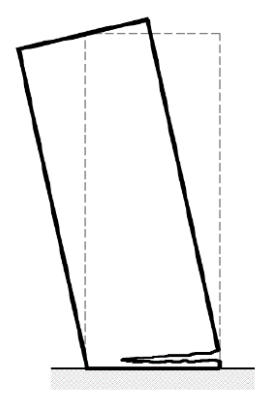

(b) single crack plastic hinge mode (under reinforced section) 

al. 2018)

\begin{tabular}{cc}
\hline Concrete Grade* & Minimum Reinforcement Ratio (\%) \\
\hline N32 & 0.7 \\
N40 & 0.8 \\
N50 & 0.9 \\
N65 & 1.0 \\
\hline
\end{tabular}

$393 *$ the concrete grade designation is based on Australian convention because Menegon et al.

394 (2018) reports the results of investigation undertaken in Australia

395 Given that the height of the stem wall $(h)$ is readily known, the only remaining input parameter

396 to Equation (5) is the wall flexural rigidity $\left(E I_{e f f}\right)$. Note that subscript eff denotes cracked

397 concrete. Three methods may be used for calculating the value of $E I_{\text {eff }}$ :

398 1. Method 1 - by moment-curvature analysis which is executable using program Response $2000($ Bentz 2000).

400 2. Method 2 - moment-curvature analysis by fibre-element analysis which can be 401 implemented on an Excel spreadsheet as proposed by Lam et al. (2011).

402 3. Method 3 - Simplified method of calculation employing Equations (6) to (8). Equation 403 (7) was derived by Priestley et al. (2007) based on extensive moment-curvature 404 analyses carried out on lightly (axially) loaded structural element which is consistent to the conditions of the stem wall of a rockfall barrier.

$$
\begin{gathered}
M_{y}=\phi M_{u}=0.8 A_{s t} f_{y}(0.9 d) \\
\phi_{y}=\frac{1.7 \varepsilon_{s y}}{D}
\end{gathered}
$$




$$
E I_{e f f}=\frac{M_{y}}{\phi_{y}}
$$

406 As shown in Figure 15, curves showing the moment-curvature relationships as calculated from

407 method nos. 1 and 2 are in very good agreement. The values of $M_{y}$ and $\phi_{y}$ were found to be

$408376 \mathrm{kNm}$ and $0.023 \mathrm{rad} / \mathrm{m}$ respectively. The slope representing the initial stiffness in the bi-

409 linear model may be taken as the value of the parameter $E I_{e f f}$. It has been found from

410 sensitivity analyses undertaken by the authors that the moment-curvature behaviour of a

411 lightly-loaded wall is insensitive to changes in the grade of concrete nor its Young's modulus.

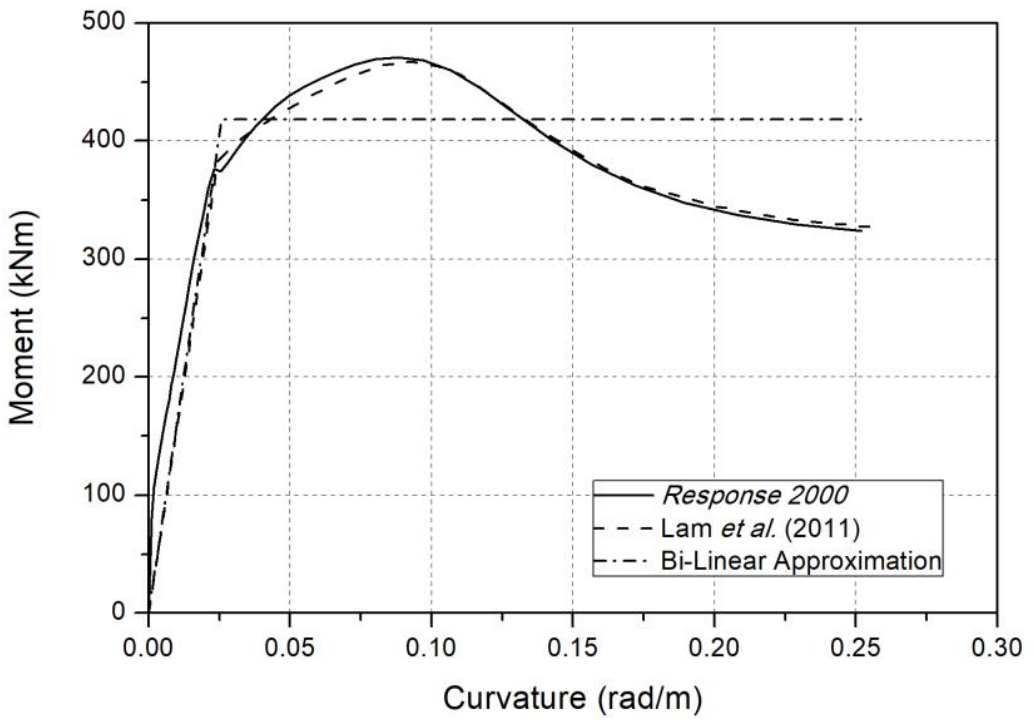

Figure 15 Moment-curvature relationship with bi-linear line of best fit

414 When applying method no. 3, parameters required for input into Equations (6) - (8) may be

415 taken from values listed in Table 6. The values of $M_{y}$ and $\phi_{y}$ can be calculated by substituting

416 the listed values into Equations (6) and (7) respectively. The resulting value of $E I_{e f f}$ is then

417 compared with that obtained from Figure 15 alongside values of $k_{e f f}$ as listed in Table 7.

418 Values of $E I_{e f f}$ and $k_{\text {eff }}$ as derived from the alternative methods of calculation have been 
found to be in very good agreement (refer Table 7). Results presented herein will be used in analyses presented in the later part of the paper.

Table 6 Parameters required for Equations (6) and (7)

\begin{tabular}{cc}
\hline Parameters & Values \\
\hline Section Depth, $D$ & $230 \mathrm{~mm}$ \\
Wall Length, $B$ & $3000 \mathrm{~mm}$ \\
Reinforcement Arrangement & N20-200 \\
Cover & $30 \mathrm{~mm}$ \\
$d^{*}$ & $170 \mathrm{~mm}$ \\
Tensile Bar Area, $A_{s t}$ & $4712 \mathrm{~mm}{ }^{2}$ \\
Yield Strength, $f_{y}$ & $543 \mathrm{MPa}$ \\
Yield Strain, $\varepsilon_{s y}$ & 0.0028 \\
Concrete Strength, $f_{c}^{\prime}$ & $47 \mathrm{MPa}$ \\
\hline
\end{tabular}

$* d$ is defined as the distance between the compressive surface of concrete and the centre of tensile reinforcing bar

Table 7 Comparison of $E I_{e f f}$ and $\boldsymbol{k}_{\text {eff }}$ values calculated from different methods

\begin{tabular}{ccc}
\hline Parameters & Figure 15 & Equations $(6)-(8)$ \\
\hline$E I_{\text {eff }}\left(k N m^{2}\right)$ & 16176 & 15139 \\
$k_{\text {eff }}(k N / m)$ & 14379 & 13457 \\
\hline
\end{tabular}

\subsection{Comparison of Predictions from the Proposed Model with Experimental Measurements}

429 All input parameters into the model are dependent on the impact scenario except for the value

430 of the $k_{\text {eff }}$ parameter which may be taken as constant: $k_{\text {eff }}=14379 \mathrm{kN} / \mathrm{m}$ across all

431 scenarios. These input parameters to Equation (2) are listed in Table 8. For Test \#1 to \#8, the

432 mass of the protective steel plate $(62.8 \mathrm{~kg})$ is considered to be part of the "target". The value 
433 of COR was calculated using Equation (3) and the velocity of impactor inferred from the HSC.

434 The predicted maximum deflection values of the stem wall as calculated using the analytical

435 solution of Equation (2) are compared with experimental measurements (refer Figure 16).

Table 8 Input parameters to Equation (2)

\begin{tabular}{ccccccc}
\hline Test \# & $m(\mathrm{~kg})$ & $\lambda m(\mathrm{~kg})$ & $\lambda$ & $v_{0}(\mathrm{~m} / \mathrm{s})$ & $v_{2}(\mathrm{~m} / \mathrm{s})$ & $\mathrm{COR}$ \\
\hline 1 & 280 & 683.8 & 2.44 & 1.93 & 0.79 & 0.41 \\
2 & 280 & 683.8 & 2.44 & 3.08 & 1.15 & 0.29 \\
3 & 280 & 683.8 & 2.44 & 4.17 & 1.47 & 0.22 \\
4 & 280 & 683.8 & 2.44 & 5.18 & 1.74 & 0.16 \\
5 & 435 & 683.8 & 1.57 & 1.55 & 0.88 & 0.46 \\
6 & 435 & 683.8 & 1.57 & 2.48 & 1.36 & 0.41 \\
7 & 435 & 683.8 & 1.57 & 3.66 & 1.89 & 0.33 \\
8 & 280 & 683.8 & 2.44 & 1.91 & 0.74 & 0.34 \\
9 & 280 & 621 & 2.22 & 1.93 & 0.79 & 0.32 \\
10 & 280 & 621 & 2.22 & 3.08 & 1.24 & 0.29 \\
11 & 280 & 621 & 2.22 & 4.26 & 1.77 & 0.34 \\
12 & 280 & 621 & 2.22 & 5.1 & 2.03 & 0.28 \\
\hline
\end{tabular}

437 In Figure 16, a sample of the maximum deflection value as calculated from the proposed model 438 is shown as a straight line when overlaid on a graph in which the time-history of the deflection 439 of the stem wall is presented. The maximum values of the deflection as obtained from 440 calculation and from experimental measurements are then compared in the form of a bar chart 441 as shown in Figure 17, and they are shown to be in good agreement. Over-predictions can be 442 seen in Test \#1 and \#2 in which case the stem wall was not fully cracked, and yet the 443 calculations were based on the assumption of a fully cracked wall (with stiffness equal to $k_{e f f}$ ).

444 In a follow-up test (Test \#8) repeating the same impact scenario (as Test \#1) on a fully cracked 445 wall, the calculated maximum deflection value was in much better agreement with the recorded 446 value. 


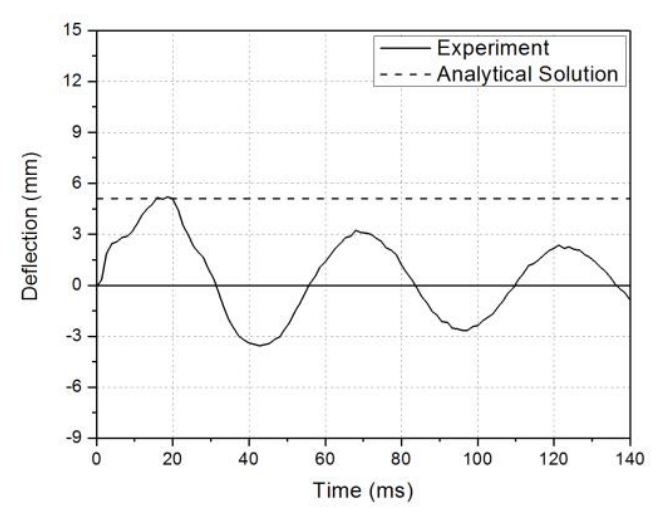

Figure 16 Comparison of deflection recorded from experiment (Test \#8) and calculated from Equation (2)

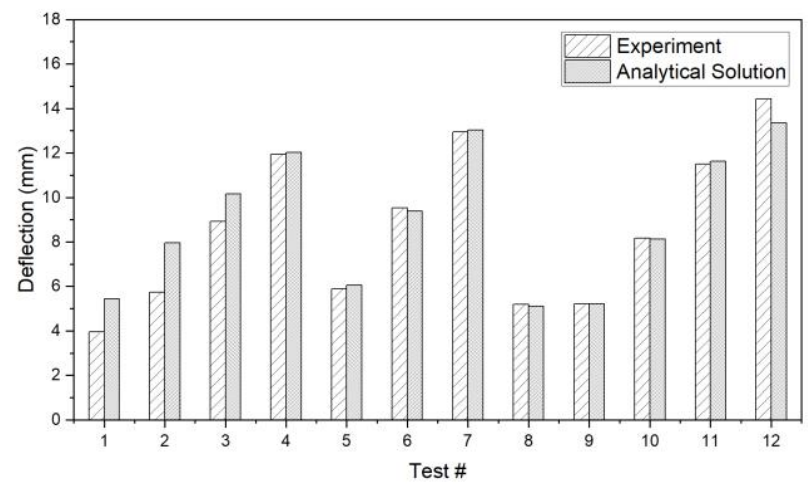

Figure 17 Maximum deflection recorded from experiments across all the tests in comparison with estimation by use of Equation (2)

\subsection{Estimation of Maximum Tensile Reinforcement Strain}

448 Given that the value of the yield curvature $\left(\phi_{y}\right)$ of the stem wall has been calculated in Section

4493.2 , being $0.023 \mathrm{rad} / \mathrm{m}$, the value of the yield deflection $\left(\Delta_{y i}\right)$ can be estimated using Equation 450 (9), being $12.1 \mathrm{~mm}$. Note that $h_{i}$ refers to the height of impact measured from the base of the 451 wall (i.e. $1.25 \mathrm{~m}$ ), and hence $\Delta_{y i}$ corresponds to the yield deflection at the same height. Yield 452 deflection at the top of the wall $\left(\Delta_{y}\right)$ can then be estimated based on fundamental mechanics of 453 material as presented by Equation (10), being $15.7 \mathrm{~mm}$.

$$
\begin{gathered}
\Delta_{y i}=\frac{\phi_{y} h_{i}^{2}}{3} \\
\Delta_{y}=\Delta_{y i}\left(\frac{3 h-h_{i}}{2 h_{i}}\right)
\end{gathered}
$$

454 The maximum strain $\varepsilon_{s}$ of the tensile reinforcement may be linearly correlated with the 455 maximum deflection of the wall as shown by Equations (11) and (12) in which the limit of 456 yield $\left(\varepsilon_{s y}\right)$ can be taken as 0.0028 (refer Section 2.1). 


$$
\begin{gathered}
\frac{\varepsilon_{s}}{\varepsilon_{s y}}=\frac{\Delta}{\Delta_{\mathrm{y}}} \\
\varepsilon_{s}=\varepsilon_{s y} \times \frac{\Delta}{\Delta_{\mathrm{y}}}
\end{gathered}
$$

457 By substituting the deflection values calculated from Section 3.3 into Equation (12), the value

458 of $\varepsilon_{s}$ for each test can be estimated by the presented analytical model. The calculated strain

459 value is shown by a straight line when overlaid on a chart presenting experimental

460 measurements from a row of strain gauges positioned at the base of the stem wall across its

461 length (refer Figure 18 for a sample display of maximum strains recorded from the array of

462 strain gauges). The maximum experimentally recorded strain value for each test is then

463 compared with the respective analytically predicted value in the form of a bar chart

464 demonstrating good agreement consistently across many tests (Figure 19). Where there are

465 discrepancies the errors are always on the safe side.

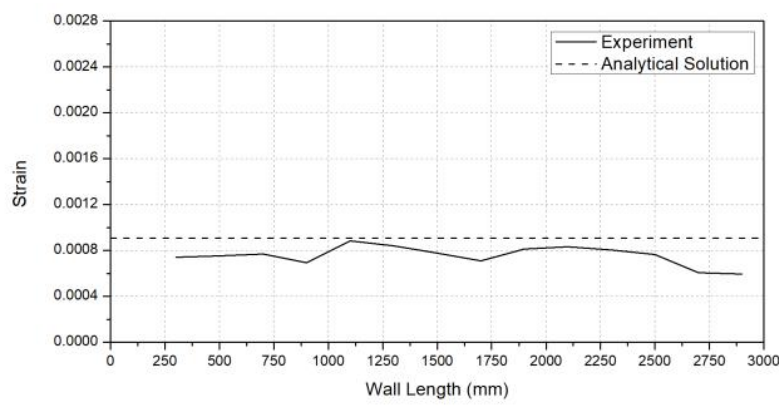

Figure 18 Tensile reinforcement strains recorded from experiment (Test \# 8) in comparison with estimation by use of Equation (12)

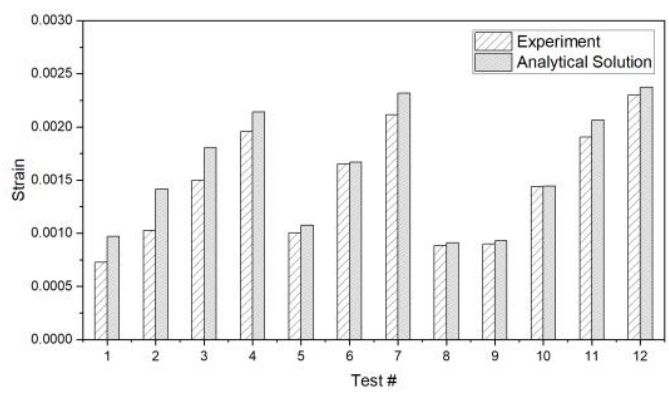

Figure 19 Maximum tensile reinforcement strains recorded from experiments across all the tests in comparison with estimation by use of Equation (12) 


\subsection{Contact Force vs Quasi-static Force}

468 The term "contact force" refers to the force developed at the point of contact between the

469 impactor object and the surface of the target, and is not to be confused with the term "quasi-

470 static force" (or "reaction force") which is defined as the force to emulate the maximum

471 deflection demand of the impact. The quasi-static force (or reaction force) can be obtained by

472 multiplying the wall deflection measured from the experiment by the estimated flexural

473 stiffness of the wall (refer Section 3.2). An example (Test \#1) of comparison between contact

474 force and quasi-static force is shown in Figure 20. It is shown in the comparison that the amount

475 of contact force delivered by the impactor is an order of magnitude larger than the actual

476 reaction force experienced by the wall at its base, and at a much shorter duration. Similar

477 observations can also be seen across all 12 tests, as demonstrated in Figure 21. The differences

478 between the two types of forces is the result of a significant amount of inertia force that can be

479 generated from within the wall when experiencing deflection in response to the impact action.

480 Thus, applying contact force in a quasi-static manner to the target would give misleading

481 predictions of the global response behaviour of the targeted structure. In summary, the

482 analytical model proposed in Section 3.1 takes into account the effects of inertial resistance to

483 accurately predict the global response behaviour of the target instead of the contact force.

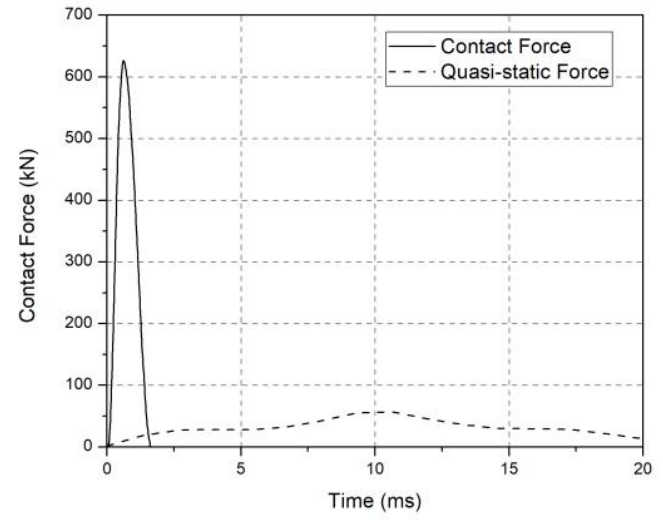

Figure 20 Comparison of experimentally measured contact force and quasi-static force (Test \#1)

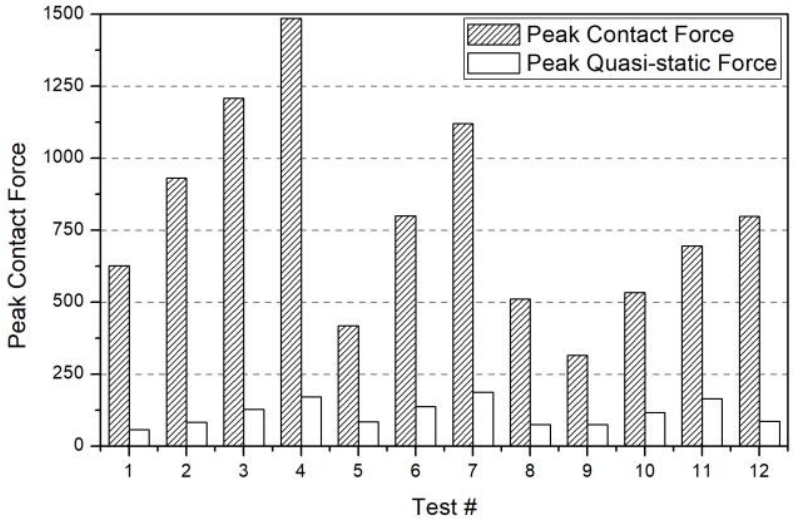

Figure 21 Comparison of experimentally measured peak contact force and quasi-static force 


\section{Conclusions}

485 This paper presents the findings and results of a recent experimental and analytical study into 486 cantilevered reinforced concrete (RC) rock fall barriers. The experimental program consisted 487 of a full-scale RC wall, which was struck with steel impactors of different sizes dropped from 488 multiple heights. The results of the experimental program were used to validate a displacement489 based (DB) method developed by the authors for predicting the impact induced flexural response of cantilevered RC walls. The main findings are summarised as follows:

1. An impact scenario cannot be defined by impact energy alone, since the ratio of the mass of the target and that of the impactor $(\lambda)$ can have a significant influence on the outcome of the impact. Experimental results show that a heavier impactor with lower velocity and equivalent impact energy can result in a significantly higher deflection demand on the wall following impact.

2. The use of the cracked stiffness (i.e. $k_{e f f}$ ) of the $\mathrm{RC}$ wall for calculating the deflection demand of the impact has been shown to give predictions that match reasonably well with experimental measurements.

3. The contact force delivered by the impact has been shown to be of much higher intensity (but lasts for a much shorter duration) than the quasi-static force, or reaction force. Thus, applying contact force on the cantilevered wall in a quasi-static manner to simulate the impact response could result in overpredicting the bending deformation of the wall.

4. The proposed DB model has been shown to provide accurate predictions of both the maximum horizontal deflection of the stem wall and the maximum tensile strain of the vertical reinforcement in the wall. 
507 This work was supported by the Australian Research Council (ARC) Discovery Project (DP)

508 entitled New Approach for Design of Barriers For Impact [grant numbers DP170101858].

\section{Notation}

510 The following notations were used in this paper:

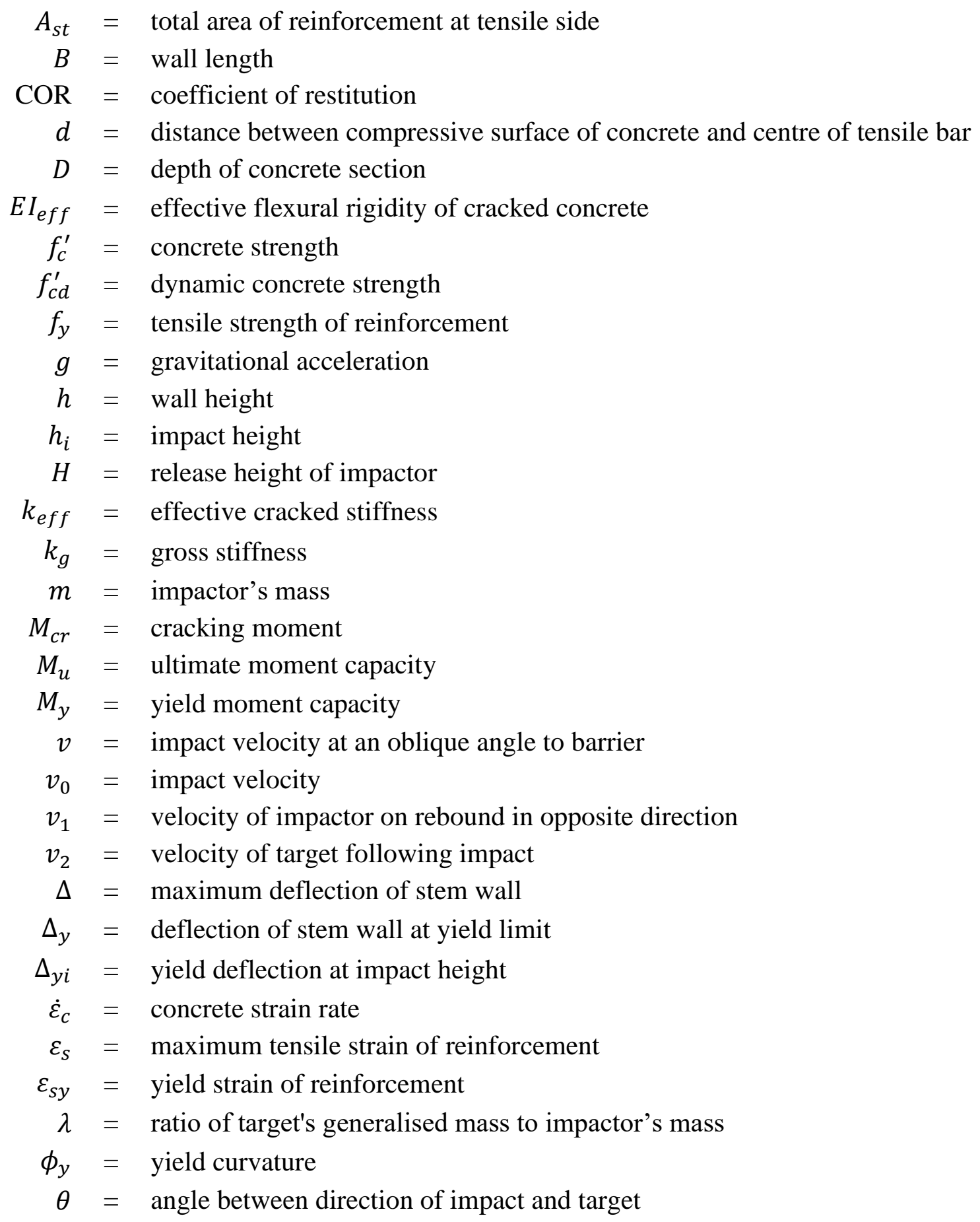


512 Adeli, H., \& Amin, A. M. (1985). Local effects of impactors on concrete structures. Nuclear

513 Engineering and Design, 88(3), 301-317.

514 Ahmed, E. A., Dulude, C., \& Benmokrane, B. (2013). Concrete bridge barriers reinforced with 515 glass fibre-reinforced polymer: static tests and pendulum impacts. Canadian Journal of Civil 516 Engineering, 40(11), 1050-1059.

517 Ali, M., Sun, J., Lam, N., Zhang, L., \& Gad, E. (2014). Simple hand calculation method for 518 estimating deflection generated by the low velocity impact of a solid object. Australian Journal 519 of Structural Engineering, 15(3), 243-259.

520 American Association of State Highway and Transportation Officials. (2012). AASHTO 521 LRFD Bridge Design Specifications, 6th edition. Washington DC, U.S.

522 Aminata, D., Yashima, A., Sawada, K., Sung, E., Sugimori, K., \& Inoue, S. (2008). New 523 Protection Wall Against Rockfall Using a Ductile Cast Iron Panel. Journal of Natural Disaster 524 Science, 30(1), 25-33.

525 ASTRA. (2008). Einwirkungen infolge Steinschlags auf Schutzgalerien (in German). 526 Richtlinie, Bundesamt für Strassen, Baudirektion SBB, Eidgenössische Drucksachen-und 527 Materialzentrale, Bern.

528 Austroads. (2013). Standardised Bridge Barrier Design. Sydney: Austroads Ltd.

529 Ben-Dor, G., Dubinsky, A., \& Elperin, T. (2006). Modeling of High-Speed Penetration Into 530 Concrete Shields and Shape Optimization of Impactors. Mechanics Based Design of Structures 531 and Machines, 34(2), 139-156.

532 Bentz, E. C. (2000). Sectional analysis of reinforced concrete members: University of Toronto 533 Toronto.

534 Berner, K. (1981). Der Einfluss der Dehngeschwindigkeit auf das mechanische Verhalten von 535 Betonstählen, 12. Forschungskolloquium des Deutschen Ausschusses für Stahlbeton, BAM, 536 Berlin.

537 Bischoff, P. H., \& Perry, S. H. (1991). Compressive behaviour of concrete at high strain rates. 538 Materials and Structures, 24(6), 425-450.

539 Chen, Y., \& May, I. M. (2009). Reinforced concrete members under drop-weight impacts. 540 Proceedings of the ICE - Structures and Buildings, 162(1), 45-56.

541 Comite Euro-Internationale du Beton. (1993). CEB-FIP model code 1990. Bulletin 542 d'Information(213-214). 
543 Dancygier, A. N., Yankelevsky, D. Z., \& Jaegermann, C. (2007). Response of high 544 performance concrete plates to impact of non-deforming projectiles. International Journal of 545 Impact Engineering, 34(11), 1768-1779.

546 El-Salakawy, E., Brière, F., Masmoudi, R., \& Benmokrane, B. (2002). Impact Test of GFRP 547 Reinforced Concrete Bridge Barriers with New Non-Metallic Connection. Paper presented at 548 the 4th Structural Specialty Conference of the Canadian Society for Civil Engineering, 549 Montréal, Canada.

550 Eurocode 1. (2008). Eurocode 1 - Actions on structures - Part 1-7: General actions - accidental actions (S.P. Committee, Ed.). London: European Committee for Standardization.

552 Fujikake, K., Li, B., \& Soeun, S. (2009). Impact Response of Reinforced Concrete Beam and 553 Its Analytical Evaluation. Journal of Structural Engineering, 135(8), 938-950.

554 Heckötter, C., \& Vepsä, A. (2015). Experimental investigation and numerical analyses of 555 reinforced concrete structures subjected to external missile impact. Progress in Nuclear Energy, $55684,56-67$.

557 Hoult, R., Goldsworthy, H., \& Lumantarna, E. (2017). Plastic Hinge Length for Lightly 558 Reinforced Rectangular Concrete Walls. Journal of Earthquake Engineering, 1-32.

559 Hu, K., Wei, F., Hong, Y., \& Li, X. (2006). Field measurement of impact force of debris flow. 560 Yanshilixue Yu Gongcheng Xuebao/Chinese Journal of Rock Mechanics and Engineering, 25, $561 \quad 2813-2819$.

562 Hu, K., Wei, F., \& Li, Y. (2011). Real-time measurement and preliminary analysis of debris563 flow impact force at Jiangjia Ravine, China. Earth Surface Processes and Landforms, 36(9), 564 1268-1278.

565 Hummeltenberg, A., Beckmann, B., Weber, T., \& Curbach, M. (2011). Investigation of 566 concrete slabs under impact load. Applied Mechanics and Materials, 82, 398-403.

567 Japan Road Association. (2000). Manual for Anti-impact Structures against Falling Rock (in 568 Japanese).

569 Jiang, T., Grzebieta, R. H., \& Zhao, X.-L. (2004). Predicting impact loads of a car crashing 570 into a concrete roadside safety barrier. International journal of crashworthiness, 9(1), 45-63.

571 Kishi, N., \& Bhatti, A. Q. (2010). An equivalent fracture energy concept for nonlinear dynamic 572 response analysis of prototype RC girders subjected to falling-weight impact loading. 573 International Journal of Impact Engineering, 37(1), 103-113.

574 Kishi, N., Okada, S.-Y., \& Kon-No, H. (2009). Numerical impact response analysis of rockfall 575 protection galleries. Structural Engineering International, 19(3), 313-320. 
576 Kojima, I. (1991). An experimental study on local behavior of reinforced concrete slabs to 577 missile impact. Nuclear Engineering and Design, 130(2), 121-132.

578 Kwan, J. S. H. (2012). Supplementary technical guidance on design of rigid debris-resisting 579 barriers (GEO Report No. 270). Retrieved from Geotechnical Engineering Office, the 580 Government of the Hong Kong Special Administrative Region:

581 Lam, C., Yong, A. C. Y., Kwan, J. S. H., \& Lam, N. T. K. (2018a). Overturning stability of Lshaped rigid barriers subjected to rockfall impacts. Landslides.

583 Lam, N., \& Gad, E. (2016). The estimation of impact forces based on first principles. Paper presented at the Australasian Structural Engineering Conference: ASEC 2016.

Lam, N., Wilson, J., \& Lumantarna, E. (2011). Force-deformation behaviour modelling of cracked reinforced concrete by EXCEL spreadsheets. Computers and Concrete, 8(1), 43-57.

587 Lam, N. T. K., Yong, A. C. Y., Lam, C., Kwan, J. S. H., Perera, J. S., Disfani, M. M., \& Gad, 588 E. (2018b). Displacement-based approach for the assessment of overturning stability of 589 rectangular rigid barriers subjected to point impact. Journal of engineering mechanics, 144(2).

590 Levings, J., \& Sritharan, S. (2012). Effects of Cold Temperature and Strain Rate on the Stress591 Strain Behavior of ASTM A706 Grade 420(60) Steel Reinforcement. Journal of Materials in 592 Civil Engineering, 24(12), 1441-1449.

593 Lu, Y. (2017). Siesmic design of lightly reinforced concrete walls. The University of Auckland.

594 Menegon, S. J., Wilson, J. L., Lam, N. T. K., \& McBean, P. (2018). RC walls in Australia: 595 seismic design and detailing to AS 1170.4 and AS 3600. Australian Journal of Structural 596 Engineering, 19(1), 67-84.

597 Mougin, J. P., Perrotin, P., Mommessin, M., Tonnelo, J., \& Agbossou, A. (2005). Rock fall 598 impact on reinforced concrete slab: an experimental approach. International Journal of Impact 599 Engineering, 31(2), 169-183.

600 Ng, C. W. W., Choi, C. E., Su, A. Y., Kwan, J. S. H., \& Lam, C. (2016). Large-scale successive 601 boulder impacts on a rigid barrier shielded by gabions. Canadian Geotechnical Journal, 53(10), $602 \quad 1688-1699$.

603 Othman, H., \& Marzouk, H. (2016). An experimental investigation on the effect of steel 604 reinforcement on impact response of reinforced concrete plates. International Journal of 605 Impact Engineering, 88, 12-21.

606 Perera, S., Lam, N., Pathirana, M., Zhang, L., Ruan, D., \& Gad, E. (2016). Deterministic 607 solutions for contact force generated by impact of windborne debris. International Journal of 608 Impact Engineering, 91, 126-141. 
609 Perera, S., Lam, N., Pathirana, M., Zhang, L., Ruan, D., \& Gad, E. (2017). Use of static tests

610 for predicting damage to cladding panels caused by storm debris. Journal of Building

611 Engineering, 12, 109-117.

612 Priestley, M. J. N., Calvi, G. M., \& Kowalsky, M. J. (2007). Displacement-Based Seismic

613 Design of Structures. Pavia, Italy: IUSS Press.

614 Rostasy, F., Scheuermann, J., \& Sprenger, K. (1984). Mechanical behaviour of some 615 construction materials subjected to rapid loading and low temperature. Betonwerk + Fertigteil-

616 Technik, 50(6), 393-401.

617 Schmidt-Hurtienne, B. (2000). Ein dreiaxiales Schädigungsmodell für Beton unter Einschluss

618 des Dehnrateneffekts bei Hochgeschwindigkeitsbelastung: Inst. für Massivbau und

619 Baustofftechnologie.

620 Standards Australia. (2004). AS5100.2 Bridge Design Part 2: Design Loads. New South Wales,

621 Australia.

622 Standards Australia. (2007). AS 1379 Specification and supply of concrete. New South Wales,

623 Australia.

624 Standards Australia. (2018). AS 3600 Concrete structures. New South Wales, Australia.

625 Standards Australia, \& Standards New Zealand. (2001). AS/NZS 4671 Steel reinforcing

626 materials. New South Wales, Australia and Wellington, New Zealand.

627 Su, Y., Chen, R., Hong, Y., Song, D., Qiao, J., \& Ng, C. W. W. (2015). Pilot study of 628 cushioning effects of gabions and other impact absorption materials subject to dynamic impact 629 load. Retrieved from Hong Kong:

630 Sun, J., Lam, N., Zhang, L., Gad, E., \& Ruan, D. (2014). Contact forces generated by fallen 631 debris. Structural Engineering and Mechanics, 50(5), 589-603.

632 Sun, J., Lam, N., Zhang, L., Ruan, D., \& Gad, E. (2016). Computer Simulation of Contact 633 Forces Generated by Impact. International Journal of Structural Stability and Dynamics. 634 Retrieved from doi:10.1142/S0219455417500055

635 Tachibana, S., Masuya, H., \& Nakamura, S. (2010). Performance based design of reinforced 636 concrete beams under impact. Natural Hazards and Earth System Science, 10(6), 1069-1078.

637 Tamagna, A., \& Riera, J. (1993). Dynamics load penetration functions for impact analysis. 638 Paper presented at the Transactions of the 12. international conference on Structural Mechanics 639 in Reactor Technology (SMiRT). Volume J: Structural dynamics and extreme loads analysis.

640 Tamagna, A., \& Riera, J. D. (1998). Low speed penetration in solids. Nuclear Engineering and 641 Design, 179(2), 125-133. 
642 Yang, Y., Lam, N. T. K., \& Zhang, L. (2012). Evaluation of simplified methods of estimating 643 beam responses to impact. International Journal of Structural Stability and Dynamics, 12(3), 644 1250016-1250011-1250016-1250024.

645 Yong, A. C. Y. (2019). Impact-resistance of Reinforced Concrete Structures.

646 Zhan, T., Wang, Z., \& Ning, J. (2015). Failure behaviors of reinforced concrete beams 647 subjected to high impact loading. Engineering Failure Analysis.

648 Zhang, M. H., Shim, V. P. W., Lu, G., \& Chew, C. W. (2005). Resistance of high-strength 649 concrete to projectile impact. International Journal of Impact Engineering, 31(7), 825-841.

650 Zhang, S. (1993). A comprehensive approach to the observation and prevention of debris flows 651 in China. Natural Hazards, 7(1), 1-23.

652 Zineddin, M., \& Krauthammer, T. (2007). Dynamic response and behavior of reinforced 653 concrete slabs under impact loading. International Journal of Impact Engineering, 34(9), 15176541534.

655 


\section{University Library}

\section{- M M I N E R VA \\ A gateway to Melbourne's research publications}

Minerva Access is the Institutional Repository of The University of Melbourne

Author/s:

Yong, ACY;Lam, NTK;Menegon, SJ;Gad, EF

Title:

Experimental and Analytical Assessment of Flexural Behavior of Cantilevered RC Walls Subjected to Impact Actions

Date:

2020-04

\section{Citation:}

Yong, A. C. Y., Lam, N. T. K., Menegon, S. J. \& Gad, E. F. (2020). Experimental and Analytical Assessment of Flexural Behavior of Cantilevered RC Walls Subjected to Impact Actions. Journal of Structural Engineering, 146 (4), pp.04020034-04020034. https:// doi.org/10.1061/(asce)st.1943-541x.0002578.

Persistent Link:

http://hdl.handle.net/11343/247735 